\title{
Recycled materials in railroad substructure: an energy perspective
}

\author{
Buddhima Indraratna $^{1} \cdot$ Yujie $\mathbf{Q i}^{1}{ }^{(1 D} \cdot$ Rakesh Sai Malisetty $^{1} \cdot$ Sinniah K. Navaratnarajah $^{2,3} \cdot$ \\ Fatima Mehmood ${ }^{1} \cdot$ Miriam Tawk $^{3,4}$
}

Received: 19 September 2021/Revised: 11 December 2021/Accepted: 11 December 2021/Published online: 27 January 2022 (C) The Author(s) 2022

\begin{abstract}
Given that the current ballasted tracks in Australia may not be able to support faster and significantly heavier freight trains as planned for the future, the imminent need for innovative and sustainable ballasted tracks for transport infrastructure is crucial. Over the past two decades, a number of studies have been conducted by the researchers of Transport Research Centre (TRC) at the University of Technology Sydney (UTS) to investigate the ability of recycled rubber mats, as well as waste tyre cells and granulated rubber to improve the stability of track substructure including ballast and subballast layers. This paper reviews four applications of these novel methods, including using recycled rubber products such as CWRC mixtures (i.e., mixtures of coal wash $(\mathrm{CW})$ and rubber crumbs (RC)) and SEAL mixtures (i.e., mixtures of steel furnace slag, CW and RC) to replace subballast/capping materials, tyre cells reinforcements for subballast/capping layer and under ballast mats; and investigates the energy dissipation capacity for each application based on smallscale cyclic triaxial tests and large-scale track model tests. It has been found that the inclusion of these rubber
\end{abstract}

Buddhima Indraratna

Buddhima.indraratna@uts.edu.au

1 Transport Research Centre, School of Civil and Environmental Engineering, Faculty of Engineering and Information Technology, University of Technology Sydney, Sydney, NSW 2007, Australia

2 Department of Civil Engineering, Faculty of Engineering, University of Peradeniya, Peradeniya, Sri Lanka

3 School of Civil, Mining and Environmental Engineering, University of Wollongong, Wollongong, NSW 2522, Australia

4 College of Engineering and Technology, American University of the Middle East, Egaila, Kuwait products increases the energy dissipation effect of the track, hence reducing the ballast degradation efficiently and increasing the track stability. Moreover, a rheological model is also proposed to investigate the effect of different rubber inclusions on their efficiency to reduce the transient motion of rail track under dynamic loading. The outcomes elucidated in this paper will lead to a better understanding of the performance of ballast tracks upgraded with resilient rubber products, while promoting environmentally sustainable and more affordable ballasted tracks for greater passenger comfort and increased safety.

Keywords Ballast degradation - Recycled rubber · Energy dissipation - Laboratory testing · Rheological model

\section{Introduction}

With the fast development of rail track technologies, the term "high-speed rail system" becomes popular worldwide, especially in Europe and Asia. High-speed rail refers to the railway service with speeds not less than $200 \mathrm{~km} / \mathrm{h}$, and the recorded fastest rail speed is $431 \mathrm{~km} / \mathrm{h}$ in China and the general high-speed rails are running with a speed of $320-380 \mathrm{~km} / \mathrm{h}$ reported by countries like Japan, South Korea, UK, Germany and Spain [1, 2]. Compared with the high-speed rail in Europe and Asia, the development of faster trains in Australia is way behind with the maximum train speed of only $160 \mathrm{~km} / \mathrm{h}$ [3]. In order to cater for the fast-growing population and supply chains of agriculture and mining sectors, a faster and effective rail network is in urgent demand in Australia. However, the current 
capability of ballasted rail tracks is inadequate to cater to faster speeds unless more resilient tracks are designed to minimise ballast degradations and track vibrations.

Innovative geo-inclusions such as geocells, geogrids and recycled rubber products have been proposed in recent years to improve the track performance and mitigate ballast degradation. The confinement of geocells (made from highdensity polypropylene) on the ballast or subballast layer could provide a three-dimensional cellular reinforcement, increase the bearing capacity of the track and reduce the track settlement and lateral dilation [4-6]. Previous studies [7-10] investigated the performance and interaction mechanisms of aggregates reinforced with geogrids (made of polypropylene or steel) and found that the ratio between the aperture size and the nominal ballast size plays a significant role on the particle-geogrid interlocking, and with the reinforcement the track bearing capacity could be increased up to $70 \%$ [11], hence efficiently reducing the track settlement. Compared to other geo-inclusions, the major advantage of recycled rubber products (e.g. rubber crumbs, rubber mats/pads/sheets and tyre cells) is the high damping property and energy absorbing capacity which could help to dissipate more energy through the deformation of rubber, hence preventing the damage of ballast and other layers from the dynamic and impact loads [12-14]. Navaratnarajah and Indraratna [15] found that the installation of under ballast mats (UBM) could reduce the ballast breakage by $35 \%-45 \%$, the vertical deformation by $10 \%-$ $20 \%$ and lateral displacement by $5 \%-10 \%$. Another study by Costa et al. [16] indicated that by introducing the ballast mats, the free-field vibrations caused by the moving trains could be reduced by $20 \mathrm{~dB}$ in the frequency range above $40 \mathrm{~Hz}$. Jayasuriya et al. [17] and Indraratna et al. [18] investigated the track performance by installing the under sleeper pads (USP) and found that USP could increase the contact area between the ballast and sleeper by $32 \%$ and reduce the concentrated stress onto ballast, hence reducing the ballast degradation efficiently. Waste car tyres with one side wall removed off (here referred to as tyre cell) were introduced by Indraratna et al. $[19,20]$ to reinforce the capping layer of rail tracks, and it was found that the tyre cell could improve the interlocking of infilled materials and increase the stiffness of the track by more than $50 \%$. Largescale laboratory tests and field tests have been conducted to investigate the recycled granular rubber mixed with ballast, and tests results indicated that the overall energy dissipation efficiency of the ballast layer was increased significantly by including rubber particles, and ballast degradation was reduced efficiently [21-24]. Indraratna et al. [25] developed a synthetic energy absorbing layer by mixing recycled rubber crumbs with mining wastes (i.e. steel furnace slag and coal wash) in lieu of traditional subballast materials, and further investigations through a large-scale physical model and a track dynamic model indicated that, by adding $10 \%$ (by mass) rubber crumbs in the waste mixture, the track specimen showed enhanced performance with less lateral dilation, ballast breakage and vibration, and higher damping and energy dissipation efficiency compared to traditional track specimens [26, 27]. After that, further studies by the authors proposed an alternative method by mixing coal wash with rubber crumbs with increased compaction energy to serve as subballast/capping layer, and a similar rubber content (i.e. $10 \%$ by mass) was recommended to ensure the mixture has superior behaviour than traditional subballast materials [28].

This paper aims to review four novel applications using rubber products in railway, including (1) CWRC mixtures (i.e., mixtures of coal wash $(\mathrm{CW})$ and rubber crumbs $(\mathrm{RC})$ ) for railway capping layer; (2) a synthetic energy absorbing layer (SEAL) using the mixtures of steel furnace slag (SFS), CW and RC; (3) using recycled tyre cells to reinforce railway capping layer; and, (4) installing under ballast mats (UBMs) for enhanced track performance. The deformation and energy dissipation behaviour of these new proposed mixtures/applications have been investigated via small-scale and large-scale laboratory tests, and a rheological track model is also developed to look into the energy dissipation capacity of the track with these recycled applications.

\section{Application 1: CWRC mixtures for capping layer}

The reuse of waste materials in engineering projects has been the subject of numerous studies in recent years. Demolition wastes [29, 30], recycled glass [31, 32], fly ash [33-35], waste rubber tyres [20, 25, 36], coal wash [37, 38] and steel furnace slag $[12,39]$ are example waste materials that can be used to replace traditional construction materials in engineering activities. Basic geotechnical properties (i.e. specific gravity $G_{\mathrm{s}}$, the maximum dry density $\gamma_{\mathrm{d} \text { max }}$, the optimum moisture content (OMC) and friction angle $\Phi^{\prime}$ ) of CW, RC and CWRC mixtures can be found in Table 1 . Most recently, a comprehensive study evaluated the properties of a mixture of coal wash $(\mathrm{CW})$ and rubber crumbs (RC) to replace the traditional capping material in railways $[28,40]$. RC was mainly added to the mixture to enhance its energy absorption property and reduce the breakage of $\mathrm{CW}$ particles.

\subsection{Energy dissipation under static loading}

The behaviour of four CWRC mixtures with $0 \%, 5 \%, 10 \%$ and $15 \% \mathrm{RC} / \mathrm{CW}$ content by mass was evaluated under 
Table 1 Basic geotechnical properties of SFS, CW, RC and their mixtures

\begin{tabular}{llllll}
\hline Materials & $\mathrm{RC}(\%)$ & $G_{\mathrm{s}}$ & $\gamma_{\mathrm{d}, \max }\left(\mathrm{kN} / \mathrm{m}^{3}\right)$ & $\mathrm{OMC}(\%)$ & $\Phi^{\prime}\left({ }^{\circ}\right)$ \\
\hline SFS & - & 3.43 & 22.9 & 11.6 & 53.4 \\
$\mathrm{CW}$ & - & 2.11 & 17.2 & 9.8 & 36 \\
$\mathrm{RC}$ & - & 1.15 & 4.4 & - & 31 \\
CWRC & 0 & 2.25 & 17.1 & $8 \%-9 \%$ & 46.1 \\
CWRC & 5 & 2.15 & 16.3 & & 44.5 \\
CWRC & 10 & 2.07 & 15.7 & & 43.9 \\
CWRC & 15 & 2.00 & 15.2 & & 49 \\
SEAL0 & 0 & 2.89 & 20.30 & 8.1 & 54.4 \\
SEAL10 & 10 & 2.51 & 17.57 & 10.0 & 50.8 \\
SEAL20 & 20 & 2.22 & 15.50 & 12.0 & 49 \\
SEAL30 & 30 & 1.99 & 13.83 & 8.3 & 47.86 \\
SEAL40 & 40 & 1.80 & 12.40 & 5.2 & 46.6 \\
\hline
\end{tabular}

static loading conditions for three confining pressures (i.e., 25,50 and $75 \mathrm{kPa}$ ) mimicking practical field conditions for a capping layer in railways. Figure 1 shows the maximum energy absorption vs. rubber content at different confining pressures. The maximum energy absorbed, $W_{\max }$, was calculated at the failure point (peak deviator stress state) using the equation below [41]:

$W_{\max }=W_{q}+W_{p}=q_{\text {peak }} \mathrm{d} \varepsilon_{q}+p^{\prime} \mathrm{d} \varepsilon_{\mathrm{v}, \text { comp }}$,

where $W_{q}$ is the work associated with the frictional resistance of particles, $W_{p}$ is the work associated with the volumetric deformation, $q_{\text {peak }}$ is the peak deviator stress, $\mathrm{d} \varepsilon_{q}$ is the deviator strain corresponding to the peak deviator stress, $p^{\prime}$ is the mean effective stress corresponding to the maximum compressive volumetric strain, and $\mathrm{d} \varepsilon_{\mathrm{v}, \text { comp }}$ is the maximum compressive volumetric strain. A detailed

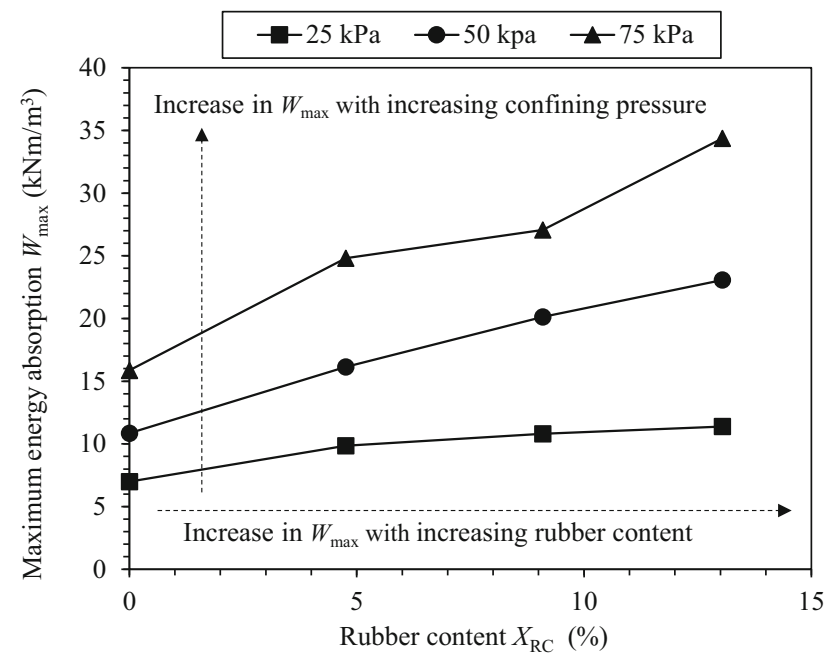

Fig. 1 Energy dissipation of CWRC mixtures under static loading (modified after Indraratna et al. [41]) derivation of this equation can be found in Indraratna et al. [41].

The maximum energy dissipated up to failure increases with increasing confining pressure, like other traditional materials. This is an expected outcome knowing that the frictional resistance, and hence, the energy associated with the frictional resistance of particles increases with enhanced confinement. More importantly, it is clear from Fig. 1 that the maximum energy dissipated increases with increasing rubber contents despite a decrease in the maximum deviator stress [40] and the work associated with frictional resistance. This proves that, despite their lower frictional strength, the inclusion of rubber particles in the mixture improves the energy dissipation potential of the mixture through the compression and deformation of these non-rigid rubber particles. This shows that rubber not only affects the maximum energy absorbed by a system, but also modifies the distribution of that energy. Part of the energy that is otherwise dissipated through friction between particles and their rearrangement is now transferred to compressible and highly deformable rubber particles, thus reducing particle breakage, and improving the energy dissipation potential of the mixture.

\subsection{Energy dissipation under cyclic loading}

In addition to static triaxial tests, CWRC mixtures were tested under cyclic loading with and without a rest period to mimic more realistic loading conditions in railways. A rest period was introduced every 40,000 cycles to observe and evaluate the rebound and recovery of compressed rubber particles every time the live load is removed. Figure 2 shows the dissipated strain energy before and after

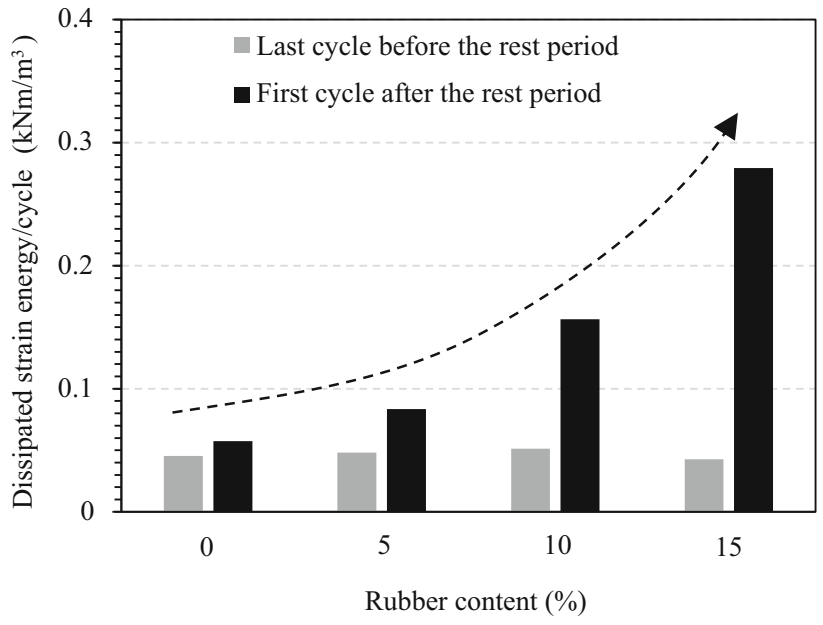

Fig. 2 Dissipated energy of CWRC mixtures under cyclic loading (modified after Tawk et al. [28]) 
the rest period for different rubber contents. The dissipated strain energy during one load cycle is calculated as the area of the hysteretic loop (the area enclosed by the loading and unloading curve). More details about the derivation can be found in [28].

It is evident from Fig. 2 that the dissipated energy during the first cycle after the rest period increases with increasing rubber contents. On the other hand, dissipated energy before the rest period, i.e., after 40,000 cycles when the mixture has undergone cyclic densification, is almost similar for all rubber contents. When the mixture reaches a shakedown state (i.e. a state where there is only minimal permanent deformation accumulation; here all the mixtures reaches the shakedown after 10,000 cycles [28]) after cyclic densification, most of the rubber particles are compressed, and their energy absorption capacity through deformation and compression becomes negligible. However, when a rest period is introduced, rubber particles partially recover their volume and with that, they recover their energy dissipation capacity that was gradually lost during cyclic densification. This indicates that a mixture with rubber particles can recover part of its energy dissipation potential when the live loads are removed, thus reducing particle breakage when the loads are applied again, as more energy will be dissipated through the compression and deformation of rubber particles rather than the frictional resistance between $\mathrm{CW}$ particles.

Breakage index (BI) which is proposed by Indraratna et al. [42] is adopted to evaluate the particle breakage of the mixtures and its definition is included in Fig. 4f. Figure 3 shows the BI of CWRC mixtures with and without a rest period for different RC contents. Indeed, the BI decreases

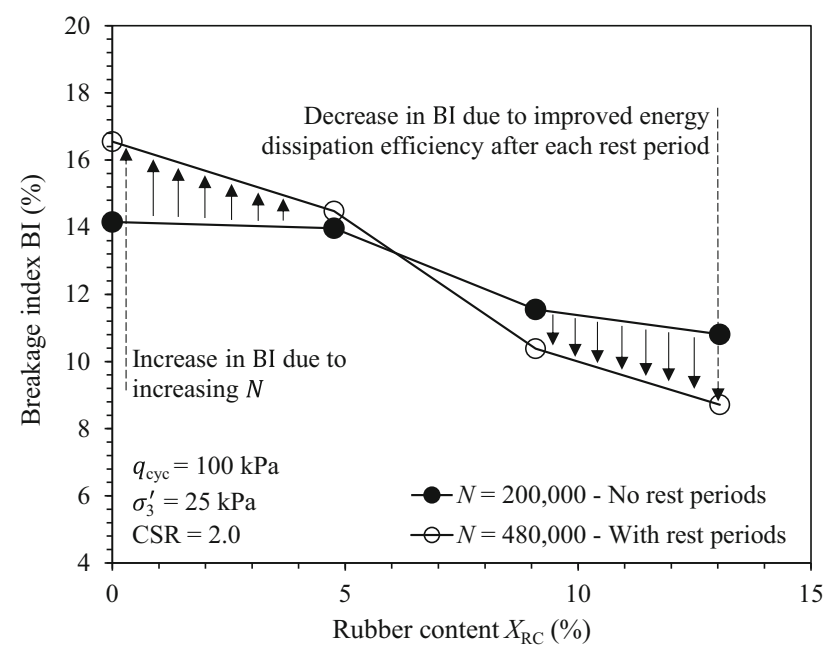

Fig. 3 Breakage index of CWRC mixtures with and without a rest period. CSR is the cyclic stress ratio, $q_{\text {cyc }}$ the maximum deviator stress, $\sigma_{3}^{\prime}$ the confining pressure, and $N$ the number of cycles (modified after Tawk et al. [28]) when rubber is added to the mixture for both conditions. In addition, for mixtures with $0 \%$ and $5 \%$ rubber content, the BI measured after 480,000 cycles with a rest period every 40,000 cycles is greater than that measured after 200,000 cycles with no rest periods. This is expected due to the higher number of loading cycles. However, when the rubber content becomes greater than $5 \%$ (i.e., $10 \%$ and $15 \%$ ), the BI measured after 480,000 cycles with a rest period is lesser than that measured after a reduced number of cycles with no rest periods. Again, this proves that with the right amount of RC in the mixture, the blend can recover part of its energy dissipation potential when a rest period is introduced and hence particle degradation can be reduced even when the mixture is subjected to a higher number of loading cycles.

\section{Application 2: a synthetic energy absorbing layer (SEAL) for subballast}

An alternative solution of using the waste mixture (rubber crumbs with mining waste) to replace traditional subballast materials was provided by Indraratna et al. [25]. Apart from $\mathrm{CW}$ and RC, steel furnace slag (SFS) was also included in the mixture to further strengthen the SEAL mixture. The general geotechnical properties of SEAL mixtures are shown in Table 1. Comprehensive laboratory tests have been conducted on the mixtures and concluded that by keeping the blending ratio of SFS:CW $=7: 3$ (by mass), the mixture could maintain sufficient shear strength with negligible swelling potential (caused by SFS) compared to traditional subballast materials [43]. Hence, all the SEAL mixtures mentioned in this study have the same blending ratio (SFS:CW $=7: 3$ ) while the $\mathrm{RC}$ content is changing from 0 to $40 \%$ (by mass).

\subsection{Proposed energy-based analysis under cyclic loading}

The purpose of replacing traditional subballast materials with SEAL mixture is to provide an energy absorbing reservoir to the track. If the total energy input by a given track load is assumed to be a certain amount, the energy applied to the ballast and the subgrade will decrease by increasing the energy absorbing capacity of the subballast layer and thus reducing the particle breakage of ballast [30].

As shown in Fig. 4, an energy consumption flowchart is established based on the comprehensive test results of the SEAL mixtures having different RC contents at confining pressure $\sigma_{3}^{\prime}=70 \mathrm{kPa}$ and number of cycles $N=10,000$ [12]. Here, the energy absorbed by the SEAL from the dynamic 


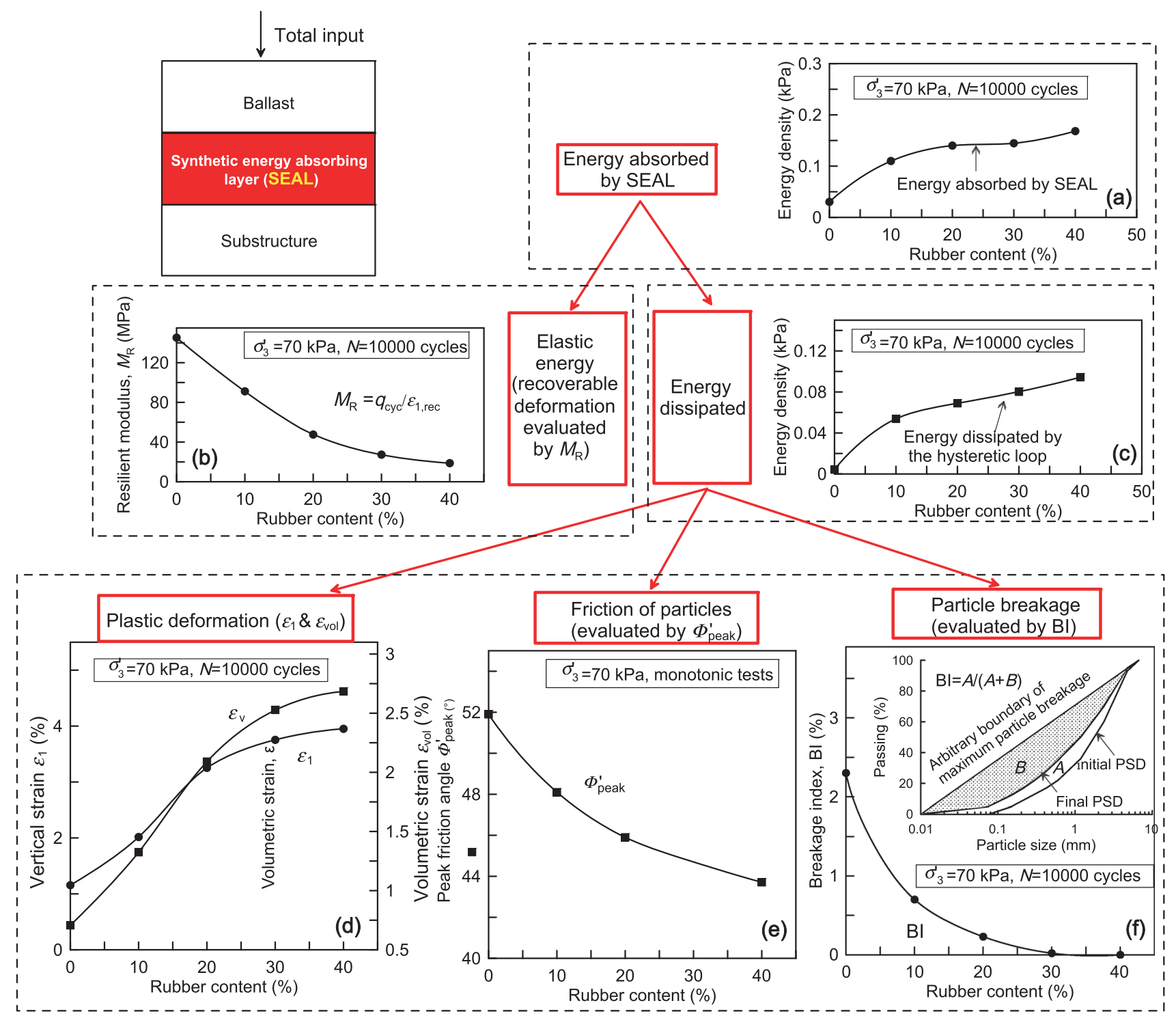

Fig. 4 Energy flow chart for SEAL in rail track: a total energy absorbed by SEAL; $\mathbf{b}$ resilient modulus; $\mathbf{c}$ dissipated energy per hysteretic loop at 1000 cycles; d vertical strain and volumetric strain after 1000 cycles; $\mathbf{e}$ friction angle of SEAL mixture tested under static loading; $\mathbf{f}$ breakage index of SEAL after 1000 cycles (modified after Qi et al. [12])

loading generally results in elastic deformation (elastic energy) or is dissipated by heat and particle breakage (dissipated plastic energy). It is noted that as RC contents increase, the energy absorbed by the SEAL increases as the area under the loading curve in the stress-strain plot increase (Fig. 4a). This indicates that less energy will be transmitted to the subgrade or the ballast layer, but accordingly, this results in more elastic energy (Fig. 4b) and dissipated energy of the SEAL (Fig. 4c). The elastic energy is related to the elastic strain (recoverable deformation) reflected by the resilient modulus $M_{\mathrm{R}}\left(M_{\mathrm{R}}\right.$ decreases, meaning that the recoverable deformation increases, Fig. 4b). The dissipated energy represented by the area of the hysteresis loop obtained from cyclic loading tests is due to (1) the permanent deformation of the waste matrix, (2) particle friction, and (3) particle breakage $[44,45]$. It is noted that the increase in dissipated energy is mainly due to the rise in the plastic deformation (both volumetric strain $\varepsilon_{\mathrm{v}}$ and axial strain $\varepsilon_{1}$ increase, Fig. 4d) as the shear strength (Fig. 4e) and particle breakage (Fig. 4f) decrease when the amount of RC increases in SEAL.

This analysis reveals that using more rubber ensures SEAL mixtures have a higher energy absorbing capacity and less particle breakage, but higher deformation, lower resilient modulus and less shear strength. By introducing SEAL in the track, it will improve the energy absorbing capacity of the whole track and reduce the ballast breakage 
but may induce more deformation as $\mathrm{RC}$ content is increased in SEAL.

\subsection{Large-scale physical model}

To further validate the aforementioned energy absorbing concept, Qi and Indraratna [26] developed a large-scale physical model using the track process simulation apparatus (TPSA) which has a test box of $800 \mathrm{~mm}$ wide, $600 \mathrm{~mm}$ long and $600 \mathrm{~mm}$ high. The model track specimen consists of three layers, i.e., ballast (depth: $200 \mathrm{~mm}$ ), subballast (depth: $150 \mathrm{~mm}$ ) and subgrade (depth: $100 \mathrm{~mm}$ ), and on the top of ballast, a concrete sleeper with rail was installed and surrounded by shoulder ballast (Fig. 5). Totally six tests were conducted by changing the subballast layer with traditional subballast materials and SEAL mixtures with $0 \%, 10 \%, 20 \%, 30 \%$ and $40 \% \mathrm{RC}$ (by mass). The test apparatus was able to measure the lateral displacement by allowing two sidewalls (perpendicular to sleeper) to move under the confining pressure of $15 \mathrm{kPa}$ and the other two sidewalls (parallel to sleeper) were fixed to simulate a plane strain condition (Fig. 5). During testing, a cyclic loading condition with the maximum deviator stress of $230 \mathrm{kPa}$ and frequency of $15 \mathrm{~Hz}$ was applied to simulate a train with a 25 -t axle load running at $110 \mathrm{~km} / \mathrm{h}$. How the field train load and speed are converted to the deviator pressure and frequency is explained below:

To mimic a 25-t axle load, the maximum rail seat load [46] is $P=40 \% \times 10 \times \frac{25,000}{2}=50 \mathrm{kN}$. The length of normal sleeper $l=2.5 \mathrm{~m}$, the width of the sleeper $b=0.26 \mathrm{~m}$, and the factor depending on the type of sleeper and the track maintenance is $\phi=1$. Therefore, the axial pressure under the sleeper is $\sigma_{1 \mathrm{cyc}}^{\prime}=\left(\frac{3 P}{b l}\right) \phi=\frac{3 \times 50}{0.26 \times 2.5} \times 1$ $=230 \mathrm{kPa}$. Following Indraratna et al. [47], the frequency is 0.138 of the train speed. Therefore, a train with a speed of $110 \mathrm{~km} / \mathrm{h}$ is equivalent to the frequency of $15 \mathrm{~Hz}$.

All the test specimens were successfully completed with 500,000 cycles except the one with SEAL40 collapsed within 2000 cycles due to severe vibration and settlement. After each test, the ballast under the sleeper was collected to determine the particle breakage. Here the number after 'SEAL' indicates the RC content within SEAL mixture. Detailed test specimen preparation and test procedure can be found in Qi and Indraratna [26, 27].

Figure 6a shows the final vertical deformation (settlement) and lateral dilation of the track specimens with traditional materials and different SEAL mixtures. It can be seen that with the increase of RC content in SEAL, the settlement increases but the lateral dilation decreases. This is highly attributed to the high compressibility of the SEAL mixtures as more rubber was included. The track specimen with SEAL40 reached a significant settlement $(48 \mathrm{~mm})$ and collapsed with severe vibration, indicating too much rubber will incur instability of the track. Compared to the traditional track specimen, the track with SEAL10 shows a promising performance with less settlement and lateral dilation. Ballast breakage is evaluated using the ballast breakage index (BBI) which is after Indraratna et al. [42]. The definition of BBI is shown in Fig. 6b where the initial and final particle size distribution curves are used. It is noted that the track with SEAL0 has a similar BBI with the traditional track, and by adding $10 \% \mathrm{RC}$ in SEAL, the BBI is reduced by $58 \%$. When more RC is included, only a minor change is observed for BBI.

The elastic and dissipated energy for the track specimen at the end of the test was calculated based on the definition shown in Fig. 7. As expected, the increase of RC in SEAL increases the elastic energy ( $\left.E_{\text {elastic }}\right)$ and the dissipated
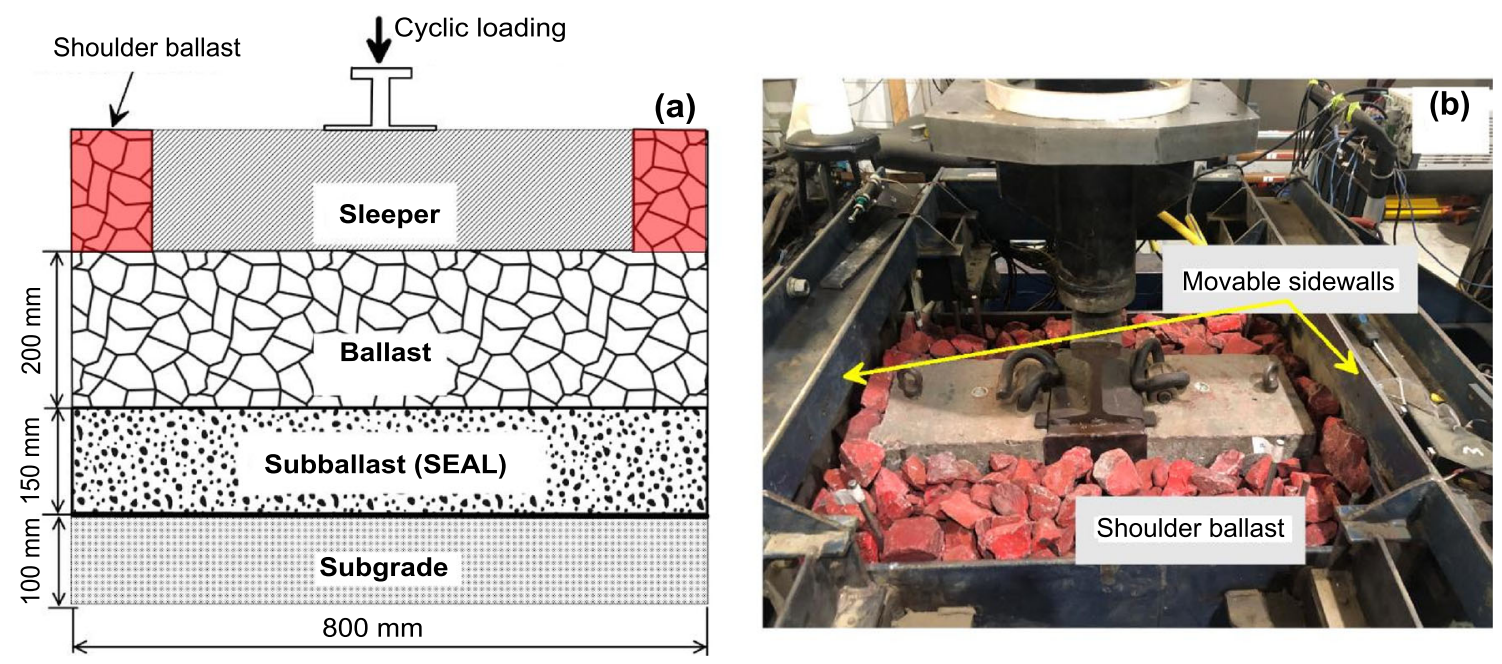

Fig. 5 a Schematic view of the large-scale physical model and $\mathbf{b}$ an overview of a prepared test specimen 


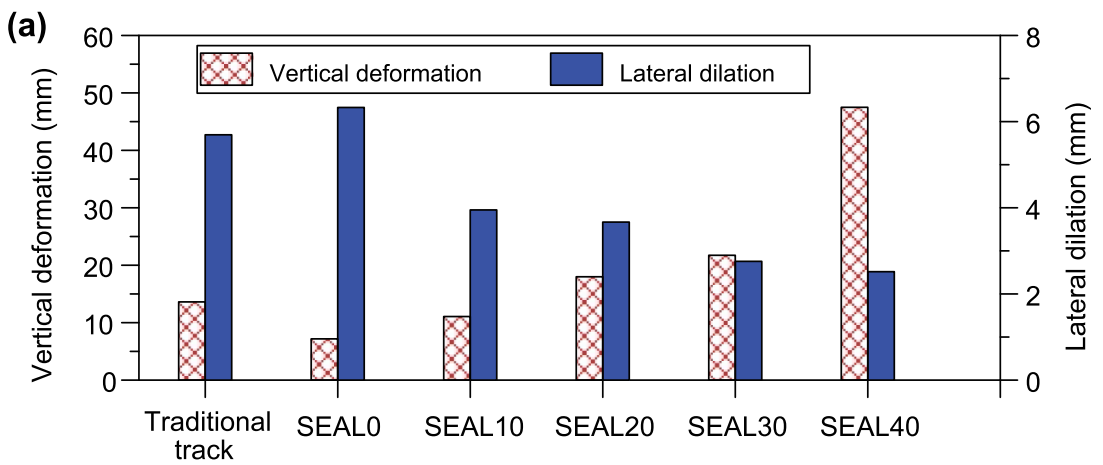

(b)

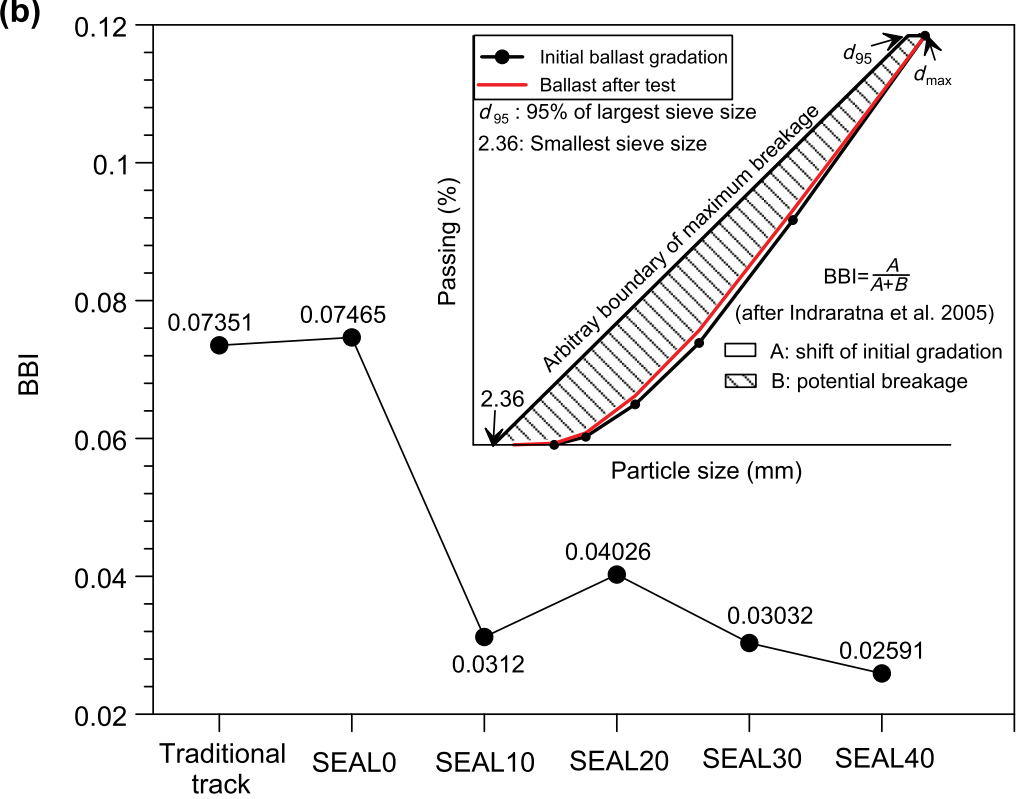

Fig. 6 a Vertical and lateral deformation and b BBI of the track specimen with different SEAL mixtures (modified after Indraratna et al. [18])

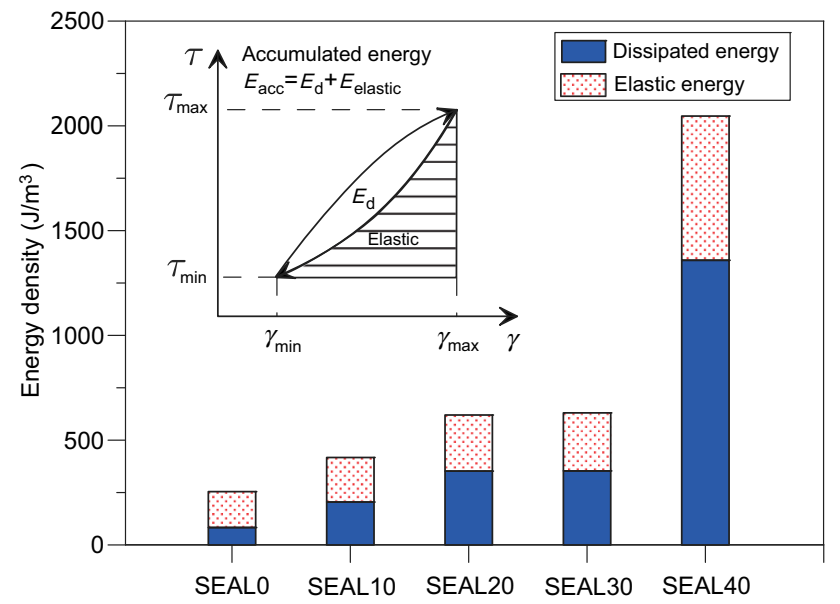

Fig. 7 Energy density of the track specimen with different SEAL mixtures at the end of the test (modified after Indraratna et al. [18]) energy $\left(E_{\mathrm{d}}\right)$ of the whole track specimen, and accordingly the total accumulated energy $\left(E_{\text {acc }}\right)$ also increases as $E_{\text {acc }}=E_{\text {elastic }}+E_{\mathrm{d}}$. This further validates the concept proposed in Sect. 3.1. The increased dissipated energy indicates more deformation and/or particle breakage when more RC is included in SEAL. However, the increased settlement and reduced ballast breakage shown in Fig. 6 suggest more energy has been allocated to deformation hence reducing the particle breakage. Therefore, the SEAL mixture which can reduce the ballast degradation without causing higher deformation is a suitable mixture to select. Based on the test results shown in Fig. 6, SEAL10 is the most promising mixture as it significantly reduces the ballast breakage and lateral dilation while showing acceptable settlement compared to traditional materials. 


\section{Application 3: tyre-cell reinforced capping layer}

The use of waste rubber tyres in the capping layer of railway track is another alternative solution investigated by Indraratna et al. [20]. A modified tyre cell is developed by removing one of the sidewalls of a waste rubber tyre. Multiple tyre cells are placed in the capping layer along the width of the railway track (Fig. 8) and are filled with a well compacted granular infill material (potentially the recycled ballast). These modified rubber tyre cells not only provide better damping characteristics due to the presence of rubber but also provide additional confinement because of the intact 3D cylindrical geometry of the tyre cell. This technology of tyre cell reinforcement in the capping layer is pending an international patent (International (PCT) Patent Application No. PCT/AU2018/050074).

\subsection{Large-scale physical model for testing tyre-cell reinforced capping layer}

Large-scale cyclic tests were conducted by Indraratna et al. [20] using TPSA to investigate the potential benefits of tyre-cell reinforced capping layer when compared to unreinforced capping layer. The materials used in these laboratory tests are fresh ballast, capping material and structural fill. For determining the response of different infill materials in the tyre cell, crushed basalt (traditional capping layer materials) and spent ballast (recycled ballast) were selected as the capping materials. The fresh ballast and crushed basalt samples were collected from a quarry near Wollongong, NSW (Australia) and the structural fill material was obtained from Hanson quarry at Kulnura, NSW (Australia). The spent ballast sample was taken from the waste stockpiles near Sydney. The gradation specifications and the compacted densities of these materials are shown in Table 2. A waste rubber tyre with an outer

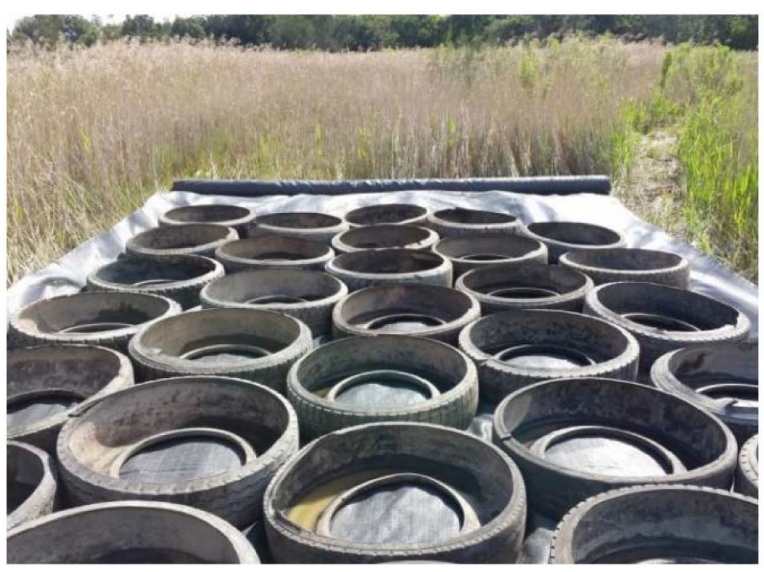

Fig. 8 Tyre cells ready to be filled with the granular infill material in a field project
Table 2 Properties of the test materials

\begin{tabular}{lllcl}
\hline Test materials & $d_{\max }(\mathrm{mm})$ & $d_{\min }(\mathrm{mm})$ & $C_{\mathrm{u}}$ & $\gamma_{\mathrm{b}}\left(\mathrm{kN} / \mathrm{m}^{3}\right)$ \\
\hline Ballast & 53 & 16 & 1.53 & 15.3 \\
Crushed basalt & 19 & 0.075 & 39.6 & 23.8 \\
Spent ballast & 63 & 19 & 1.57 & 16 \\
Structural fill & 26.5 & 0.075 & 53.3 & 21.4 \\
\hline
\end{tabular}

$d_{\max }$ and $d_{\min }$ are the maximum and minimum particle diameters, respectively; $C_{\mathrm{u}}$ is coefficient of uniformity; and $\gamma_{\mathrm{b}}$ is the maximum dry density

diameter of $560 \mathrm{~mm}$, rim diameter of $330 \mathrm{~mm}$ and width of $150 \mathrm{~mm}$ was used after cutting one of its sidewalls. Four rubber samples were extracted from another waste rubber tyre of the same specifications, and tensile tests according to ASTM D4885-01 [48] were performed on those samples. The average tensile strength of the tyre rubber at $2 \%$ and $5 \%$ strain came out to be 4.7 and $17.8 \mathrm{MPa}$, respectively.

A schematic diagram of the test setup in TPSA with tyre-cell reinforced capping layer is shown in Fig. 9. Structural fill material was placed and compacted at the base of the box. On top of the structural fill layer, a tyre cell instrumented with strain gauges was placed and filled with spent ballast or crushed basalt as the infill. A woven geotextile (having a tensile strength of 4 and $8 \mathrm{kN} / \mathrm{m}$ at $2 \%$ and $5 \%$ strain, respectively) was placed beneath the tyre cell as a separator. A ballast layer of $150 \mathrm{~mm}$ thickness was placed on top of the capping layer. The test materials were compacted in layers with a vibratory hammer to achieve the desired densities. The concrete sleeper and rail assembly was placed on the top of the compacted ballast and the gap between the sleeper and the test box walls was filled with the crib ballast. The test specimens were prepared with and without rubber tyre cells in the capping layer of two different infill materials, and thus, four test specimens were prepared in total.

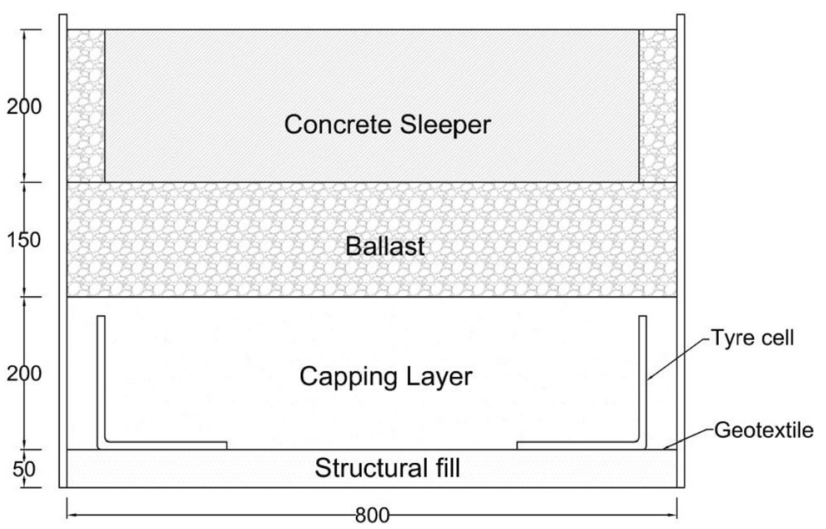

Fig. 9 Schematic of the test setup in the large-scale track process simulation apparatus 
The tests were performed with the application of a deviator stress of $370 \mathrm{kPa}$ at a frequency of $15 \mathrm{~Hz}$ (equivalent of a 40-t axle load with a train speed of $110 \mathrm{~km} / \mathrm{h}$ ). A small confining stress of $10 \mathrm{kPa}$ was applied with hydraulic jacks in the lateral direction to replicate the field conditions of a track under low confinement. Each test was completed with 500,000 loading cycles.

\subsection{Performance of tyre-cell reinforced capping layer}

The tyre cell-reinforced granular layer performs better than the traditional capping layer of a railway track due to the increased confinement provided by the assembly of tyre cells. The confined granular materials have a higher bearing capacity rendered by the interfacial friction between the tyre cell wall and the infill material. The arrest of the infill material prevents its spread in the lateral direction, and resultantly, the deformations in the ballast layer are reduced [20]. The enhanced loading bearing characteristics of this tyre-cell reinforced layer causes it to transfer less load on the top of subgrade, and thus, the significant deformations in the case of soft-soil subgrade can be prevented.

Upon loading and unloading, the materials like ballast depict hysteresis behaviour and dissipate the strain energy. This phenomenon of storing and dissipating the mechanical strain energy relates to the damping property of the viscoelastic materials. The inclusion of the rubber tyre in the railway track will certainly enhance its damping characteristics in response to the heavy dynamic loads imparted by the freight trains. The values of damping ratio $(D)$ and dissipated strain energy $\left(E_{\mathrm{d}}\right)$ for the tested specimens are

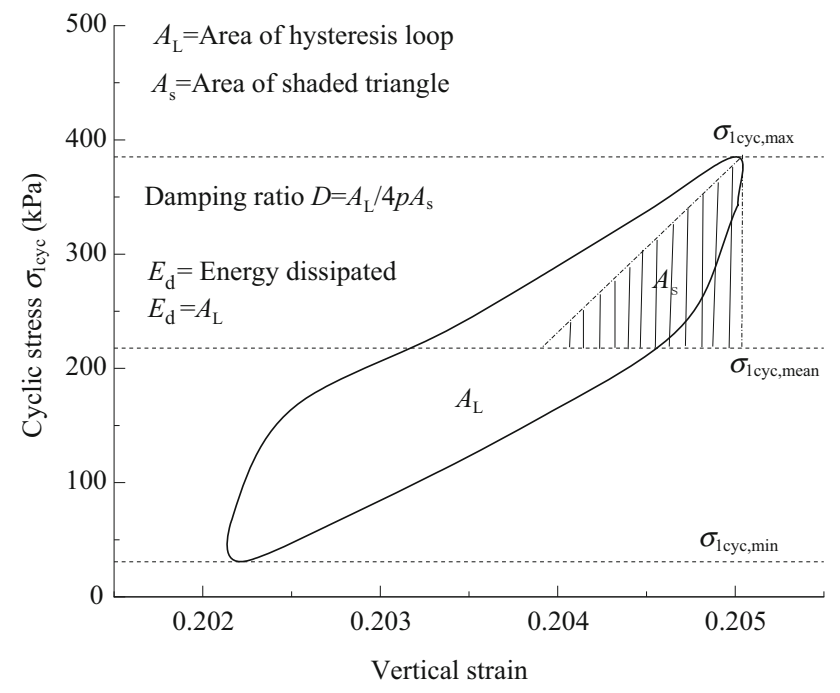

Fig. 10 Schematic of hysteresis loop showing damping ratio and dissipated energy

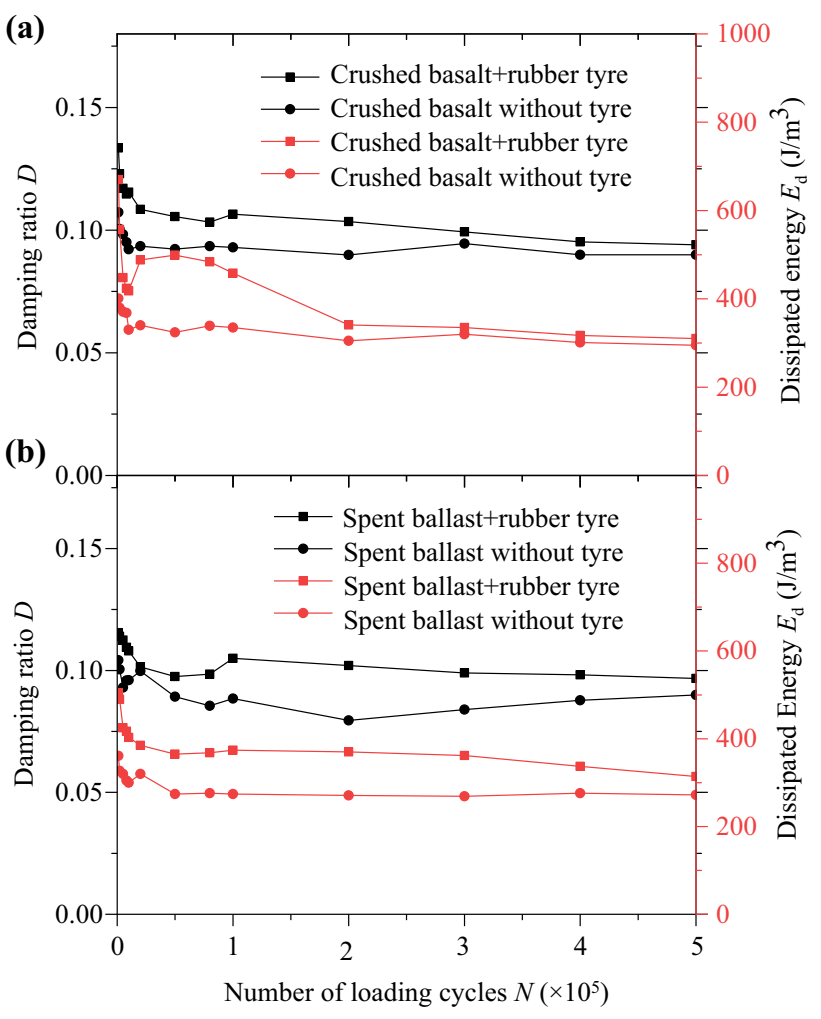

Fig. 11 Variation in the damping ratio and dissipated energy with the number of loading cycles: a reinforced and unreinforced samples with infilled crushed basalt; $\mathbf{b}$ reinforced and unreinforced samples with infilled spent ballast (modified after Indraratna et al. [50])

determined from the force-displacement response, and the procedure adopted for this calculation is given in ASTM D3999 [49]. Relevant mathematical expressions are presented in the schematic hysteresis loop shown in Fig. 10.

The change in the values of $D$ and $E_{\mathrm{d}}$ with the number of cycles $(N)$ for the reinforced and unreinforced samples is shown in Fig. 11. The results show that the addition of a rubber tyre improves the damping characteristics of the system, with an increase in the strain energy dissipated regardless of the infilled materials (Fig. 11). For the initial loading cycles up to 10,000 , the values of $D$ and $E_{\mathrm{d}}$ decrease with $N$ due to the high dissipation of energy caused by particle breakage and sliding. However, with higher $N$ values, the $D$ and $E_{\mathrm{d}}$ values become almost constant due to the densification and stabilization of the granular materials. This increase in energy dissipation can significantly contribute towards reducing the ballast degradation and thus the massive cost savings associated with the ballast maintenance. This environment-friendly approach can also reduce the burden on the quarries for the production of natural materials.

Amongst all the substructure layers of the railway track, the ballast absorbs most of the repeated dynamic wheel loading and hence, it experiences substantial particle 
breakage [51]. To assess the particle degradation, the ballast sample directly beneath the sleeper was colour-coded with white paint during the sample preparation phase. At the end of each test, the breakage mode of the ballast particles was checked and the most distinct modes observed included the particle splitting, corner breakage and attrition of the edges. The particle size distribution of the ballast samples determined after each test is shown in Fig. 12. The noticeable change in the ballast particles is in the range of size $37.5 \mathrm{~mm}$ as observed from Fig. 12. The BBI was calculated from these curves as explained in Fig. 12. The values of BBI are comparatively lower for the samples having rubber tyre cell reinforcement. For instance, a reduction in BBI of $37.6 \%$ and $68.5 \%$ is observed with a tyre cell infilled with spent ballast and crushed basalt, respectively. This is in accordance with the improved damping of the substructure as mentioned before in Fig. 11. In conclusion, the use of rubber tyre cells will render more stability to the railway track because of the increased confinement of the granular materials and enhanced damping of the track contributing to less ballast breakage.

\section{Application 4: UBM for stiff subgrade conditions}

Rail pads (RPs), under sleeper pads (USPs) and under ballast mats (UBMs) are three commonly used rubber elements in rail tracks. The RPs are installed at the railsleeper contact interface, USPs placed at the sleeper-ballast interface and the UBMs are laid below the ballast layer at the ballast-subgrade interface. While the RPs are to protect the sleepers, especially concrete sleepers from

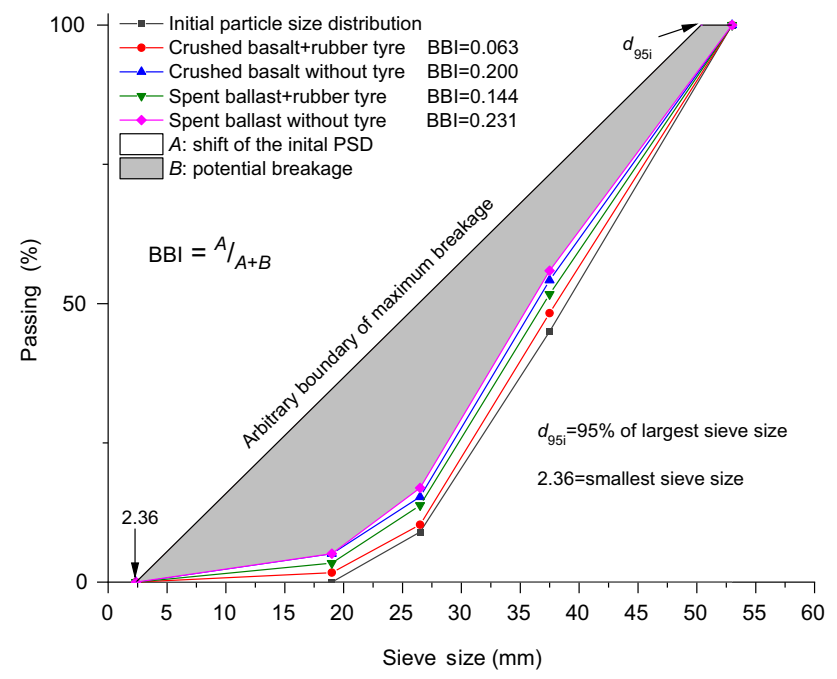

Fig. 12 Particle size distribution curves of the ballast specimens before and after each test (modified after Indraratna et al. [50]) wearing and impacting by the rail, the USPs and UBMs are mainly used to protect the ballast layers in contact with very hard surfaces such as concrete sleepers at the top of the ballast layer and very stiff subgrade at the bottom of ballast layer, respectively. The rail track substructure conditions at bridges and tunnels are quite different from a regular open track substructure. The layer below the ballast is very stiff and in general the thickness of the ballast is also limited in these isolated locations. Therefore, the ballast layer is subjected to greater stresses and faster deterioration. This issue becomes even more critical for shared corridors where faster passenger trains and heavy haul trains are operated on the same tracks. The use of UBMs in these stiff substructure sections is beneficial to reduce excessive ballast deterioration and also counterbalance the adverse effects associated with limited ballast depth. In this view, a large-scale laboratory study was undertaken to investigate the stress-strain, degradation and energy dissipation behaviour of ballast stabilised with UBMs placed over stiff subgrade.

The resilient rubber elements are generally made of rubber, polyurethane elastomers (PE), high-density polyethylene (HDPE), thermoplastic polyester elastomer (TPE) and ethylene vinyl acetate (EVA) [52, 53]. However, the use of resilient rubber materials made of waste tyres for various civil engineering related work has been popular in recent times [15, 54-56]. In this study, locally manufactured UBMs using waste tyres were used. A $10 \mathrm{~mm}$ thick rubber mat was placed underneath the ballast layer on top of the concrete base simulating a stiff subgrade condition. The static and dynamic properties of the UBM were evaluated in the laboratory as per the testing standards stipulated in [57]. The average stiffness properties obtained from three samples tested are static stiffness $\left(C_{\text {stat }}=0.2 \mathrm{~N} / \mathrm{mm}^{3}\right)$ and the dynamic stiffness $\left(C_{\mathrm{dyn} 1}=0.46\right.$ to $\left.0.59 \mathrm{~N} / \mathrm{mm}^{3}\right)$ for the loading frequencies 5 to $30 \mathrm{~Hz}$. Figure 13 shows the static and dynamic stiffness test results of one representative sample (UBM Sample 1).

\subsection{Large-scale prismoidal triaxial test}

Large-scale cyclic loading tests were carried out using the track process simulation apparatus (TPSA). This prototype test apparatus simulates realistic stress-strain boundary conditions experienced at the real track substructure [15]. The triaxial chamber of the TPSA shown in Fig. 5 has four moveable vertical walls where the lateral principal stresses and the resistance for the lateral movement can be applied independently mimicking a straight railway track. The integrated substructure layer inside the triaxial chamber consists of a 150-mm-thick concrete base at the bottom simulating a stiff subgrade condition (e.g. bridge or concrete deck), overlain by a $300 \mathrm{~mm}$ layer of compacted 


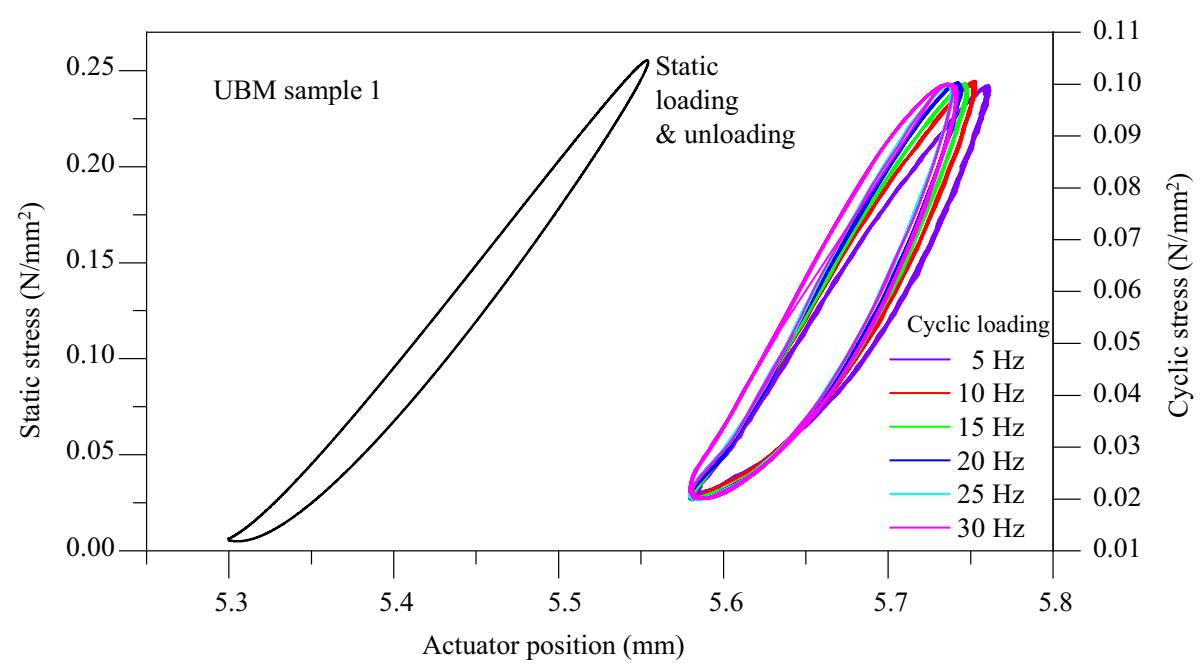

Fig. 13 Static and dynamic stiffness of the UBM

ballast, and the rail-sleeper system was placed on top of the ballast layer to apply cyclic loads by the TPSA cyclic actuator as shown in Fig. 5b. Each of the $100 \mathrm{~mm}$ ballast layers (top, middle and bottom layers) were colour-coded to calculate the variation of ballast breakages in three different levels. The space around the rail-sleeper system was filled with crib ballast up to the level of the sleeper.

The sidewalls in the lateral direction (perpendicular to sleeper) were allowed to move with the confining stress of $15 \mathrm{kPa}$ simulating a lateral resistance provided by a typical shoulder ballast, and the movement was measured using linear variable differential transformers (LVDTs). However, the walls in the longitudinal direction (parallel to the sleeper) were fixed in position $\left(\varepsilon_{2}=0\right)$, but the stress exerted to the wall by the ballast was measured using a load cell-hydraulic jack system. The cyclic load was applied by the actuator of the TPSA simulating 25-t axle load (typical passenger train) and 35-t axle load (typical freight train), with the varying loading frequencies of 15,20 and $25 \mathrm{~Hz}$ for 25-t axle load tests and 10, 15 and $20 \mathrm{~Hz}$ for 35-t axle load tests. Typical loading cycles with corresponding cyclic stress parameters are shown in Fig. 14. All the tests were conducted with and without placing a $10 \mathrm{~mm}$ UBM at the ballast-concrete base interface. A total of 500,000 load cycles were applied for each test. In addition to continuous data throughout the 500,00 cycles, a high-frequency load and deformation data were collected at the selected cycles of $N=100,500,1,000,5,000,10,000,50,000,10,0000$ and

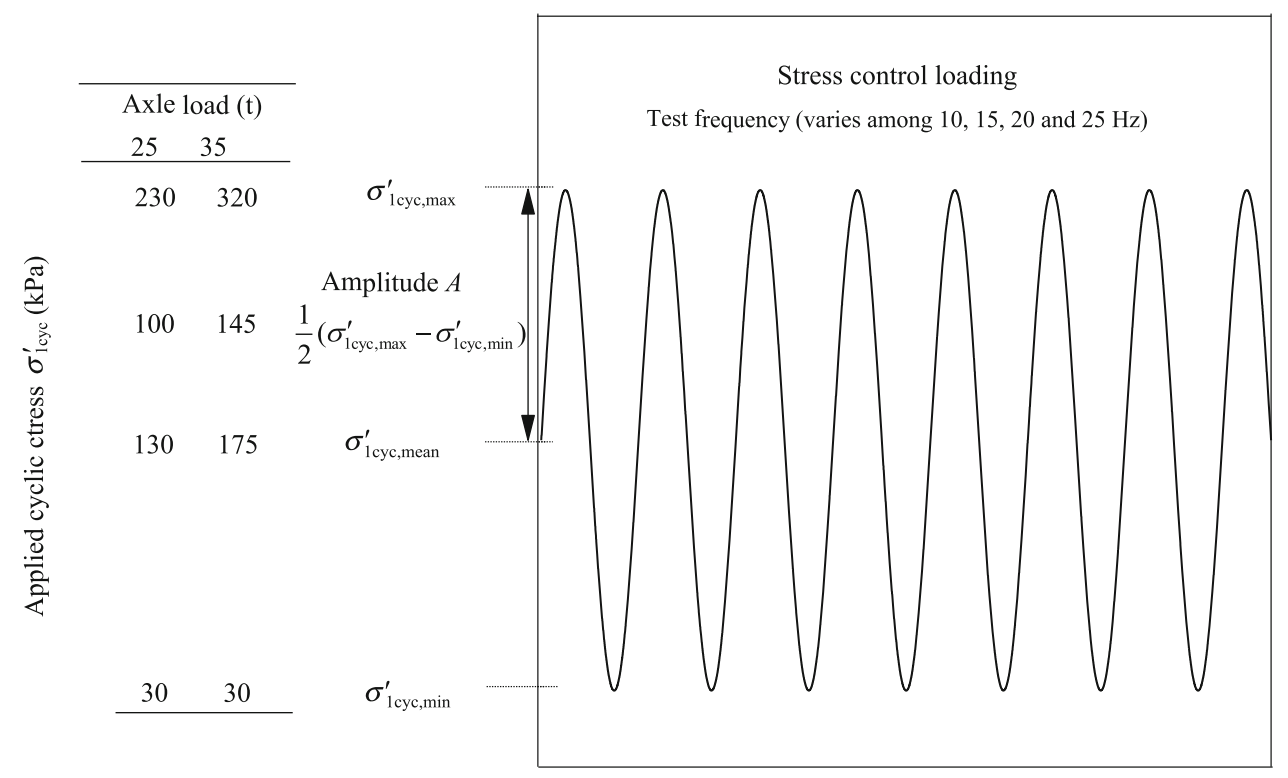

Fig. 14 Cyclic load wave with cyclic stress parameters 
thereafter every 100,000 cycles. At the end of the test, the three ballast layers were separated according to the colour and sieved through a standard sieve for the ballast breakage analysis.

\subsection{Shear and volumetric strains}

The accumulated plastic strains in the vertical $\left(\varepsilon_{1}\right)$ and lateral $\left(\varepsilon_{3}\right)$ directions for 25 - and 35 -t axle loads for various loading frequencies were calculated with and without UBM for the aforementioned load cycles. The shear $\left(\varepsilon_{\mathrm{s}}\right)$ and volumetric $\left(\varepsilon_{\mathrm{vol}}\right)$ strains were evaluated and the variation against the number of load cycles $(N)$ are presented in Fig. 15. As per the results, during the first 10,000 cycles, the shear and volumetric strains increased rapidly and then steadily reached a stable zone around 100,000 cycles as shown in Fig. 15. After the 100,000 cycles, the rate of increment in strains are decreased markedly with the load cycles and reached a near-zero strain rate. The results in Fig. 15 show that the shear and volumetric strains are increasing with the axle load and loading frequency (train speed). As per results, the shear and volumetric strains increased by about $45 \%$ when axle load increased from 25 to $35 \mathrm{t}$. Except for the loading frequency increase from 10 to $15 \mathrm{~Hz}$ frequency range, the increase of shear and volumetric strains is over $50 \%$ for every $5 \mathrm{~Hz}$ increase in the loading frequency for both $25-$ and 35 -t axle loads. It is also evident from this study that there is about $8 \%-22 \%$ reduction in the shear and volumetric strain for a $25-\mathrm{t}$ axle load, and about $8 \%-16 \%$ reduction for that of a 35-t axle load when testing the integrated layer by inserting a UBM at the ballast-concrete base interface.

(a)

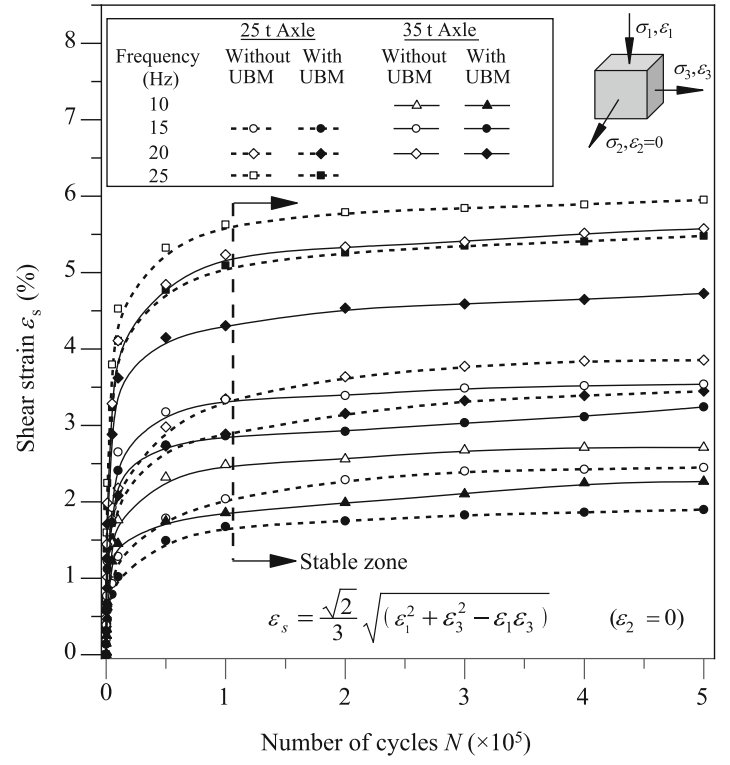

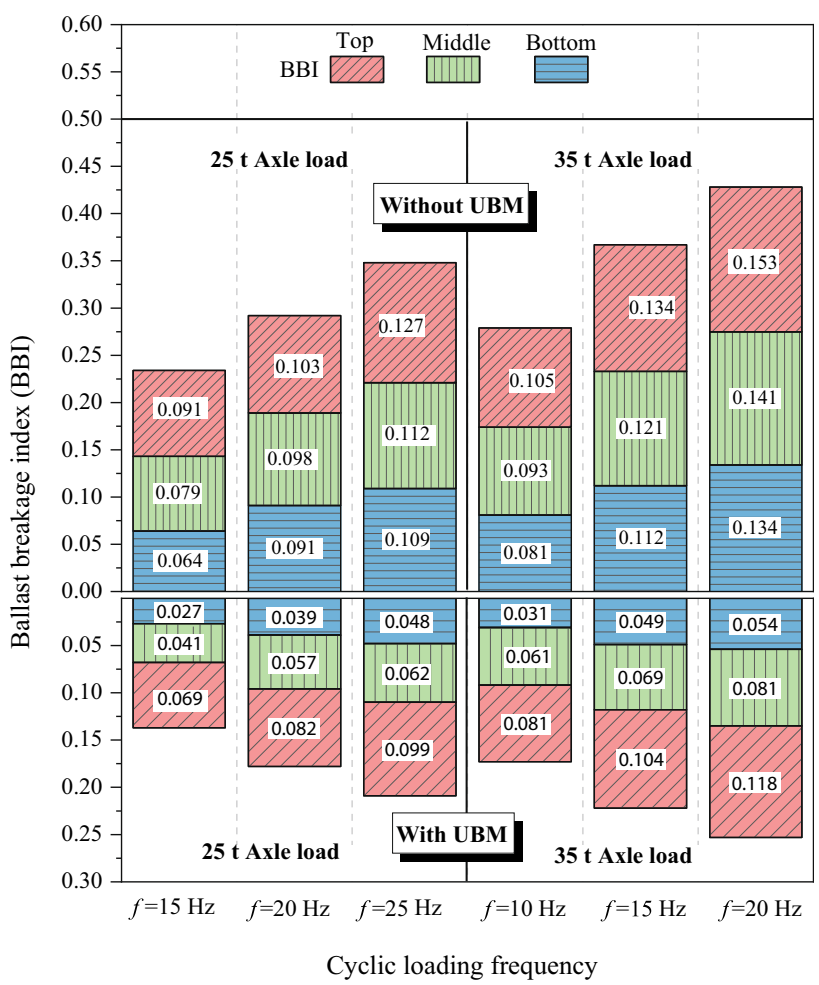

Fig. 16 Ballast breakage index (BBI) variation with axle load, load frequency and with and without UBM (modified after Navaratnarajah and Indraratna [15])

\subsection{Ballast degradation}

Figure 16 shows the BBI value computed for each of the three $100 \mathrm{~mm}$ ballast layers (top, middle and bottom) for various testing by changing load and loading frequencies

(b)

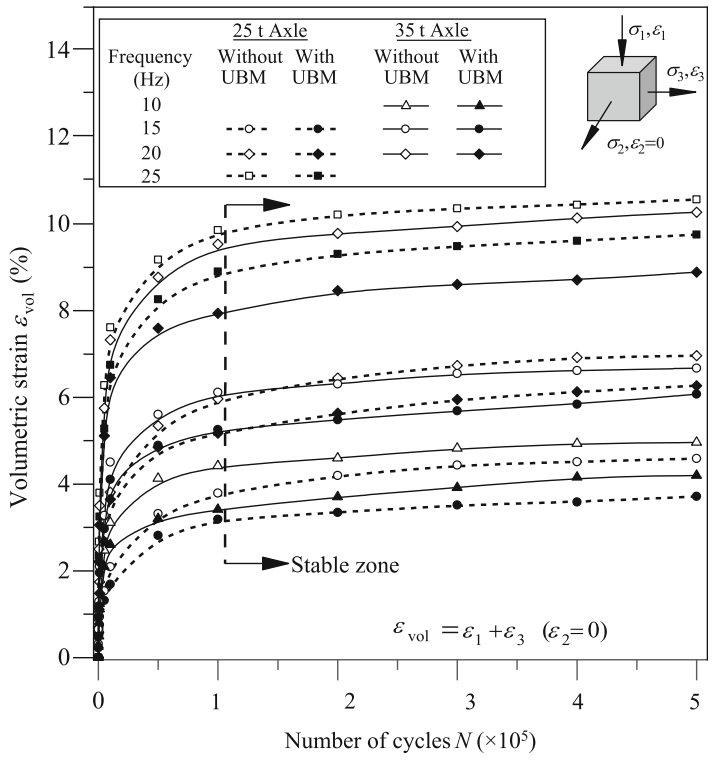

Fig. 15 Variation of $\mathbf{a}$ shear and $\mathbf{b}$ volumetric strains with number of loading cycles (modified after Navaratnarajah and Indraratna [15]) 
and also with and without UBM placed on top of the concrete base to stabilise the ballast layer. The BBI was the highest at the top layer followed by the middle and the bottom layers as the induced cyclic stress decreases with depth. As with ballast strain, ballast degradation also increases with axle loads and loading frequency. The results clearly indicate that axle loads are more significant in damaging the ballast layer than the loading frequency. However, when a UBM layer is used to stabilise the stiff subgrade condition, the ballast breakage decreases significantly as per the results shown in Fig. 16. On average, by considering the breakage of all the layers, the ballast degradation lessened by about $35 \%$ to $45 \%$ by the UBM. By using UBM, the resilient element makes a uniform contact between the ballast and concrete base at the interface and contributes to reducing the stresses in the ballast layer. In addition, much of the energy due to dynamic stresses were absorbed by the UBM because of its excellent energy absorbing capacity. This eventually reduces the energy transferred to the ballast layer and contributes to the reduction of ballast breakage.

\subsection{Energy dissipation}

Granular particles under dynamic stress undergo various forms of energy transformation such as elastic strain energy, kinetic energy, and dissipation due to particle sliding and breakages [58, 59]. The insertion of UBM materials also significantly contributes to transferring the energy exerted by the moving axle loads. However, quantifying the energy dissipated by ballast in the form of particle breakage and plastic sliding is a challenging task. The cyclic stress-strain curve developed from the laboratory test results was used to determine the strain energy dissipation by the integrated layer system with and without UBM. The dissipated energy during cyclic loading is proportional to the area within the hysteresis loops. At the point of selected load cycles, 30 hysteresis loops were obtained with high-frequency transient data. These data are then used with a MATLAB program to calculate the average energy dissipation $\left(E_{\mathrm{d}}\right)$ per unit volume for one complete load-unload cycle at the selected representative load cycle. Using the representative energy for these selected cycles, the total actual dissipated energy for the entire 500,000 load cycles $\left(E_{\mathrm{Da}}\right)$ has been evaluated.

Based on the plastic strain and degradation values, an empirical model was developed to predict the total energy dissipation $\left(E_{\mathrm{Dp}}\right)$ per unit volume of ballast by adding the corresponding dissipation terms attributed to plastic sliding $\left(E_{\mathrm{S}}\right)$ and particle breakage $\left(E_{\mathrm{B}}\right)$ :
$E_{\mathrm{Dp}}=E_{\mathrm{S}}+E_{\mathrm{B}}$.

A larger amount of energy is consumed to overcome the inter-particle frictional resistance. Therefore, the frictional sliding term $E_{\mathrm{S}}$ is closely linked to the applied deviator stress $\left(q_{\mathrm{d}}\right)$ and the total shear strain $\left(\varepsilon_{\mathrm{s}}\right)$. Evaluation of particle breakage (BBI) can be represented by the second term $E_{\mathrm{B}}$. Based on that, the following empirical expression can be proposed:

$E_{\mathrm{S}}=a\left(q_{\mathrm{d}} \varepsilon_{\mathrm{S}}\right)$,

$E_{\mathrm{B}}=b(\kappa \times \mathrm{BBI})^{c}$,

$\kappa=\sqrt{L_{\mathrm{a}} / L_{\mathrm{m}}}$,

where $a, b$ and $c$ are empirical model parameters ( $a$ and $c$ are dimensionless while $b$ takes the units of energy); $\kappa$ is the axle load factor normalised to the minimum axle load $\left(L_{\mathrm{m}}\right)$, and $L_{\mathrm{m}}=20 \mathrm{t}$ for Australian standard heavy haul; $L_{\mathrm{a}}$ is the axle load simulated in this study.

As per Eq. 4, for a standard 20-t applied axle load (i.e. $\kappa=1), b=1 \mathrm{MJ} / \mathrm{m}^{3}$ for complete particle breakage (i.e. $\mathrm{BBI}=1)$.

The non-linear regression model predicts the dissipation of energy quite well with the calculated model parameters shown in Fig. $17\left(R^{2}>0.98\right)$. While the field data are very limited to support the above relationship between actual $\left(E_{\mathrm{Da}}\right)$ and predicted $\left(E_{\mathrm{Dp}}\right)$, the Singleton field data [60] from the State of NSW as shown in Fig. 17, where UBM was placed on top of the concrete bridge deck, provided very good agreement for heavy haul traffic $(50 \mathrm{Mt})$ over 500,000 cycles at an average train speed of $70-80 \mathrm{~km} / \mathrm{h}$ (approximately equivalent to $10 \mathrm{~Hz}$ in laboratory cyclic load testing).

\section{Rheological track model with rubber inclusions}

The primary purpose of rubber inclusions in a railway track is to absorb and dissipate the mechanical energy induced by the moving train. In this section, this energy dissipation mechanism is studied using a simple rheological model of railway track, where multiple layers of a railway track substructure are represented using a series of mass springdashpot elements. The energy dissipated in different layers is analysed with respect to different combinations of track inclusions discussed in the previous sections. Their performance under impact loads generated by trains due to wheel flats or rail indentations is investigated. The dynamic sleeper-ballast interface stresses are adopted from the field tests conducted by Indraratna et al. [61] in Australia as shown in Fig. 18. 


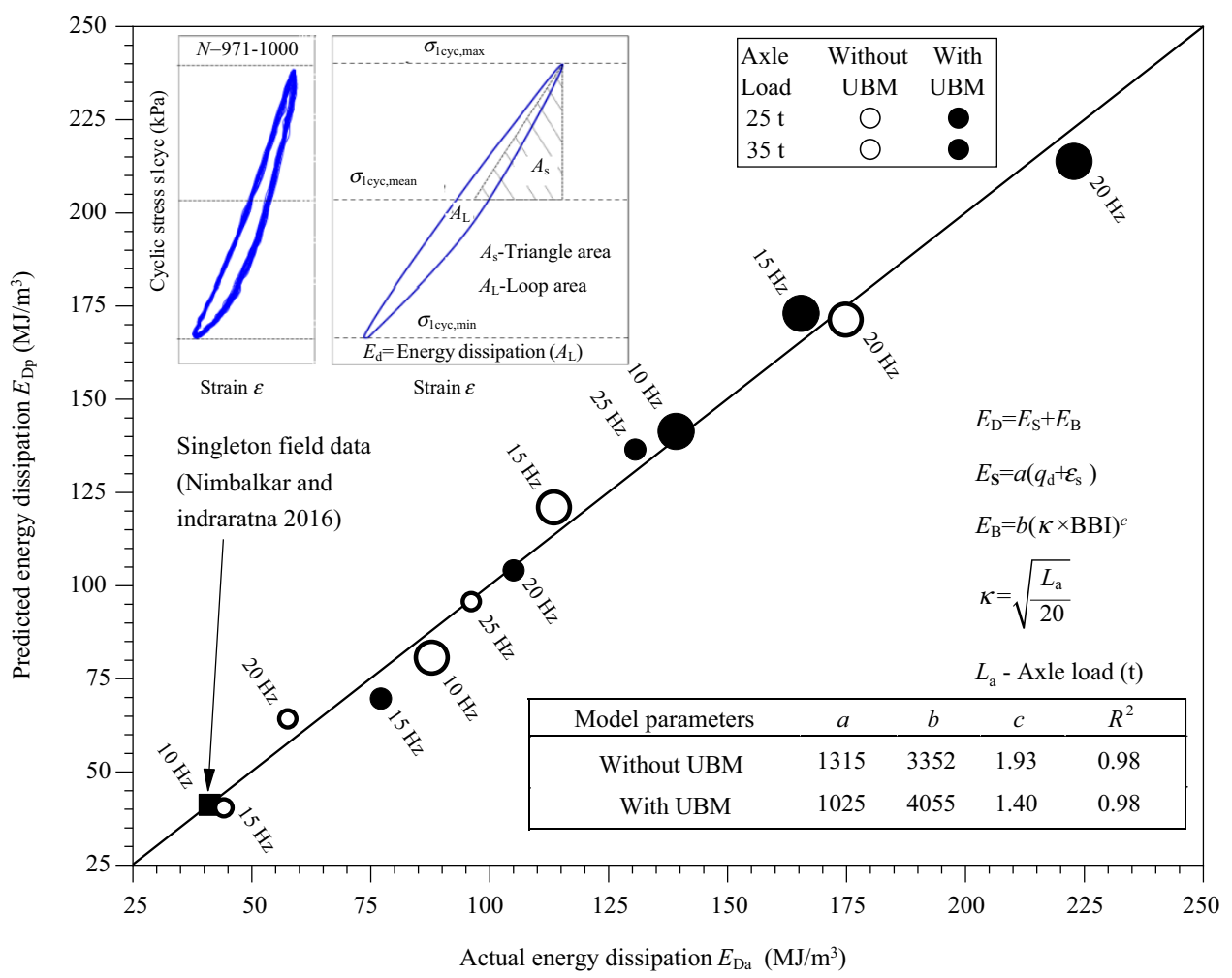

Fig. 17 Actual $\left(E_{\mathrm{Da}}\right)$ and predicted $\left(E_{\mathrm{Dp}}\right)$ energy dissipation (modified after Navaratnarajah and Indraratna [15])

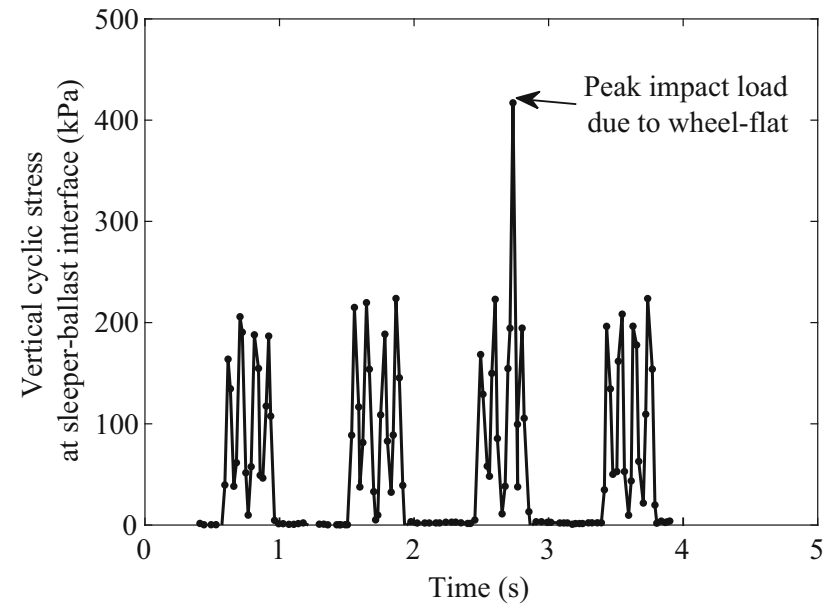

Fig. 18 Field measurement of dynamic stresses induced at the sleeper-ballast interface due to coal wagon (modified from Indraratna et al. [61])

A schematic of the mass damper system of track substructure with different track layers and elements adopted for the rheological model is shown in Fig. 19. Ballast, capping and subgrade layers are considered as mass elements with stiffness and damping. For implementing SEAL and CWRC mixtures, railway track on an embankment is considered as shown in Fig. 19a and for implementing the

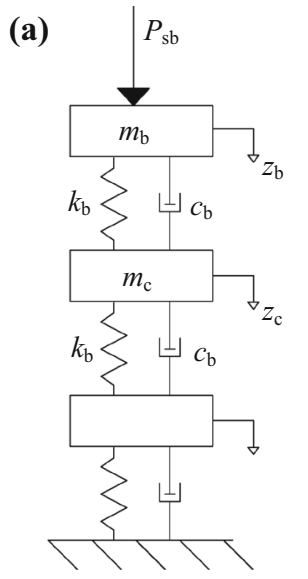

(b)

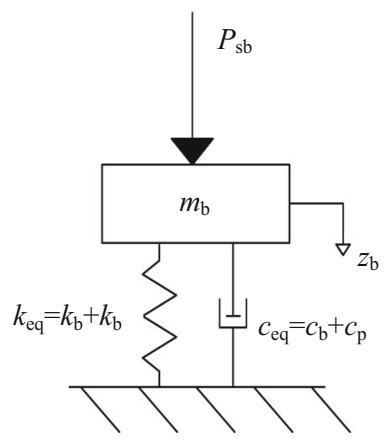

Fig. 19 Rheological models of ballasted railway track on a embankment with rubber inclusions and $\mathbf{b}$ concrete bridge deck

shock mats, and a rigid concrete bridge deck is considered as subgrade as shown in Fig. 19b. Since the introduction of shock mats increase the shear modulus and damping characteristics of ballast layer, an equivalent spring-damper system is considered for ballast while using these inclusions. The equations of motions of different elements considering the dynamic equilibrium can be derived in matrix form as 


$$
\begin{aligned}
& {\left[\begin{array}{ccc}
m_{\mathrm{b}} & 0 & 0 \\
0 & m_{\mathrm{c}} & 0 \\
0 & 0 & m_{\mathrm{s}}
\end{array}\right]\left[\begin{array}{c}
\ddot{z}_{\mathrm{b}} \\
\ddot{z}_{\mathrm{c}} \\
\ddot{z}_{\mathrm{s}}
\end{array}\right]} \\
& +\left[\begin{array}{ccc}
c_{\mathrm{b}} & -c_{\mathrm{b}} & 0 \\
-c_{\mathrm{b}} & c_{\mathrm{b}}+c_{\mathrm{c}} & -c_{\mathrm{c}} \\
0 & -c_{\mathrm{c}} & c_{\mathrm{c}}+c_{\mathrm{s}}
\end{array}\right]\left[\begin{array}{c}
\dot{z}_{\mathrm{b}} \\
\dot{z}_{\mathrm{c}} \\
\dot{\mathrm{s}}_{\mathrm{s}}
\end{array}\right] \\
& +\left[\begin{array}{ccc}
k_{\mathrm{b}} & -k_{\mathrm{b}} & 0 \\
-k_{\mathrm{b}} & k_{\mathrm{b}}+k_{\mathrm{c}} & -k_{\mathrm{c}} \\
0 & -k_{\mathrm{c}} & k_{\mathrm{c}}+k_{\mathrm{s}}
\end{array}\right]\left[\begin{array}{c}
z_{\mathrm{b}} \\
z_{\mathrm{c}} \\
z_{\mathrm{s}}
\end{array}\right] \\
& =\left[\begin{array}{c}
P_{\mathrm{sb}} \\
0 \\
0
\end{array}\right], \\
& m_{\mathrm{b}} \ddot{z}_{\mathrm{b}}+c_{\mathrm{eq}} \dot{\mathrm{z}}_{\mathrm{b}}+k_{\mathrm{eq}} z_{\mathrm{b}}=P_{\mathrm{sb}} .
\end{aligned}
$$

In Eq. 6, $m_{\mathrm{b}}, m_{\mathrm{c}}$ and $m_{\mathrm{s}}$ represent the mass, $c_{\mathrm{b}}, c_{\mathrm{c}}$ and $c_{\mathrm{s}}$ represent the damping coefficients, and $k_{\mathrm{b}}, k_{\mathrm{c}}$ and $k_{\mathrm{s}}$ represent the stiffness of ballast, capping and subgrade elements, respectively; $z_{\mathrm{b}}, z_{\mathrm{c}}$ and $z_{\mathrm{s}}$ are the displacements, $\dot{z}_{\mathrm{b}}, \dot{z}_{\mathrm{c}}$ and $\dot{z}_{\mathrm{s}}$ are the velocities, and $\ddot{z}_{\mathrm{b}}, \ddot{z}_{\mathrm{c}}$ and $\ddot{z}_{\mathrm{s}}$ are the accelerations in the vertical direction of ballast, capping and subgrade elements, respectively; $P_{\mathrm{sb}}$ is the equivalent load on the sleeper-ballast interface computed from dynamic stress $\sigma_{\mathrm{d}}$ and equivalent area under a railway sleeper $A_{\mathrm{e}}$, using $P_{\mathrm{sb}}=A_{\mathrm{e}} \sigma_{\mathrm{d}}$. The dynamic stress due to impact load in this study is considered as $\sigma_{\mathrm{d}}=$ $430 \mathrm{kPa}$ for a time of $5 \mathrm{~ms}$. For the SDOF (single degree of freedom) system in Fig. 19b, the $3 \times 3$ matrices are reduced to $1 \times 1$ matrices with mass of ballast $\left(m_{\mathrm{b}}\right)$, stiffness $\left(k_{\text {eq }}\right)$ and damping coefficient $\left(c_{\text {eq }}\right)$ as shown in Eq. $6 \mathrm{~b}$, where $k_{\text {eq }}$ and $c_{\text {eq }}$ represent the combined stiffness and damping coefficient of ballast and shock mat, respectively. Please note that when shock mat is not used, $k_{\text {eq }}$ reduces to the $k_{\mathrm{b}}$, while $c_{\text {eq }}$ reduces to $c_{\mathrm{b}}$. The equivalent mass and stiffness of each layer are computed using the trapezoidal distribution of stresses in each layer and the stress distribution angles for each layer as described in Punetha et al. [62]. The material parameters adopted in this study are given in Table 3. The dynamic shear modulus and damping ratio of ballast, SEAL mixtures and CWRC mixtures are computed using the hysteresis loops from dynamic triaxial tests from Qi et al. [12] and Tawk et al. [28]. Equations 6a,b can be solved using Newmarks- $\beta$ numerical approximation theorem and the time interval for computations is taken for reasonable accuracy in response.

To evaluate the effectiveness of these rubber inclusions, two parameters are analysed in this study which include vertical displacement response of ballast $z_{\mathrm{b}}$ and energy dissipation ratio $E_{\mathrm{dr}}$ of the system. $E_{\mathrm{dr}}$ is computed as the ratio of energy dissipated $E_{\mathrm{d}}$ by through damping loss to the total mechanical energy $E_{\mathrm{M}}$ generated by the load as given in Eq. $7(\mathrm{a}-\mathrm{c})$ :

$E_{\mathrm{dr}}=\frac{E_{\mathrm{d}}}{E_{\mathrm{M}}}$

$E_{\mathrm{M}}=\int_{0}^{t} \dot{\boldsymbol{z}}^{\mathrm{T}} \boldsymbol{M} \ddot{\boldsymbol{z}} \mathrm{d} t+\int_{o}^{t} \dot{\boldsymbol{z}}^{\mathrm{T}} \boldsymbol{K} \boldsymbol{z} \mathrm{d} t$,

$E_{\mathrm{d}}=\int_{0}^{t} \dot{z}^{\mathrm{T}} \boldsymbol{C} \dot{\mathrm{z}} \mathrm{d} t$

where $z, \dot{z}$ and $\ddot{z}$ are displacement, velocity and acceleration matrixes, respectively; $\boldsymbol{M}$ is the mass matrix; $\boldsymbol{K}$ is stiffness matrix; $\boldsymbol{C}$ is damping coefficient matrix.

Figure 20a shows the dynamic displacements in ballast when subjected to an impact load with and without shock mats. At the time of impact, peak vertical displacements are observed in the ballast layer which attenuate with time after the removal of load, eventually reaching a steady state where the displacements are completely attenuated. It can be clearly seen that the shock mats reduced the peak displacement at the moment of impact by about $40 \%$ from 0.7 to $0.4 \mathrm{~mm}$, while also aiding in quick attenuation of response with time. This attenuation in displacements is also observed from Fig. 20b as the energy dissipation ratio $\left(E_{\mathrm{dr}}\right)$ reaches 1 at the steady state indicating that the total energy generated by the load is dissipated by the damping of the system. Figure $20 \mathrm{~b}$ also shows that the time taken for the system to reach the steady state is reduced by $85 \%$ from 0.12 to $0.017 \mathrm{~s}$ when shock mats are used.

For the railway track on the embankment, the transient response of dynamic displacements of ballast with time for impact loads is shown in Fig. 21. Three cases are analysed:

Table 3 Material parameters used in the rheological model $[12,15,28$, 60, 63, 64]

\begin{tabular}{lllllll}
\hline Parameter & Ballast & Shock mat (UBM) & Capping layer & SEAL10 & CWRC10 & Stiff subgrade \\
\hline Thickness $(\mathrm{mm})$ & 300 & 10 & 150 & 150 & 150 & 500 \\
Elastic modulus (MPa) & 142 & - & 140 & 62 & 45 & 150 \\
Unit weight $\left(\mathrm{kN} / \mathrm{m}^{3}\right)$ & 15.3 & - & 21 & 17 & 16 & 20 \\
Stiffness $(\mathrm{N} / \mathrm{m})$ & - & $72 \times 10^{6}$ & - & - & - & - \\
Damping ratio & 0.03 & - & 0.09 & - & - & 0.22 \\
Damping coefficient $(\mathrm{Ns} / \mathrm{m})$ & - & $0.99 \times 10^{5}$ & - & - \\
\hline
\end{tabular}



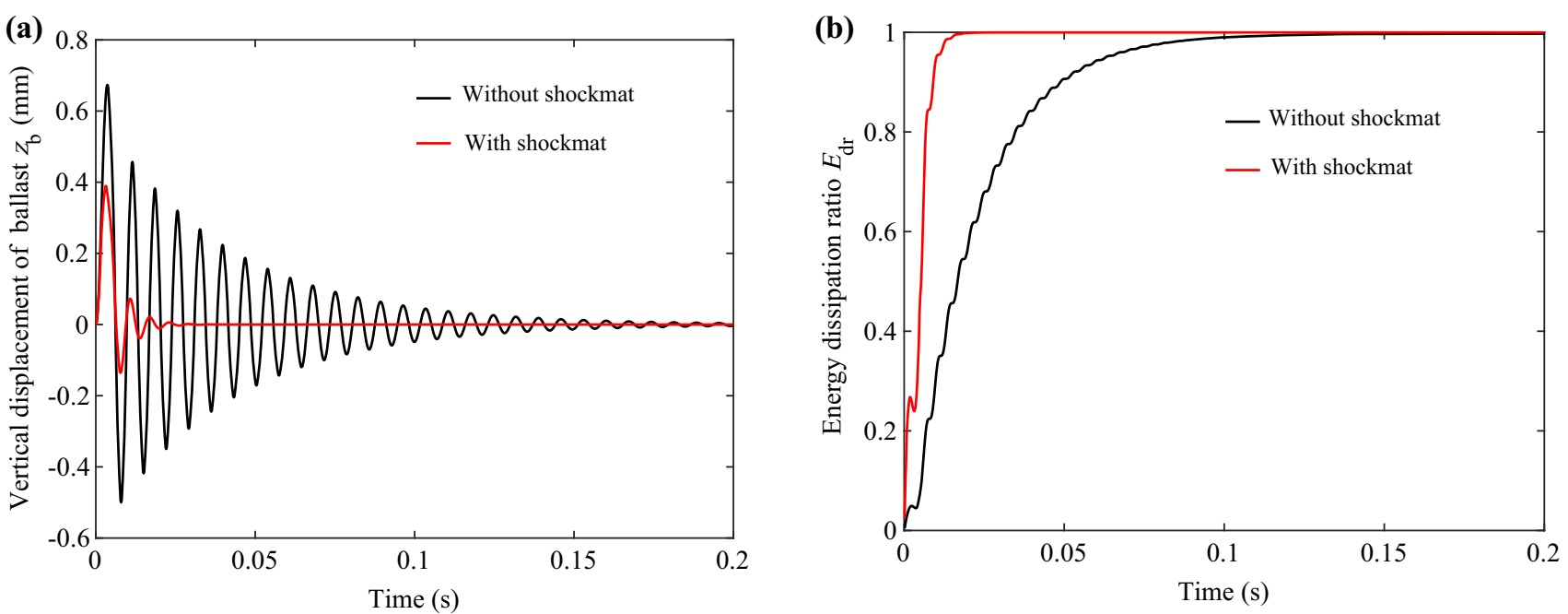

Fig. 20 Influence of rubber shock mats on a displacement attenuation with time $\mathbf{b}$ energy dissipation in the system under impact loads

(a)

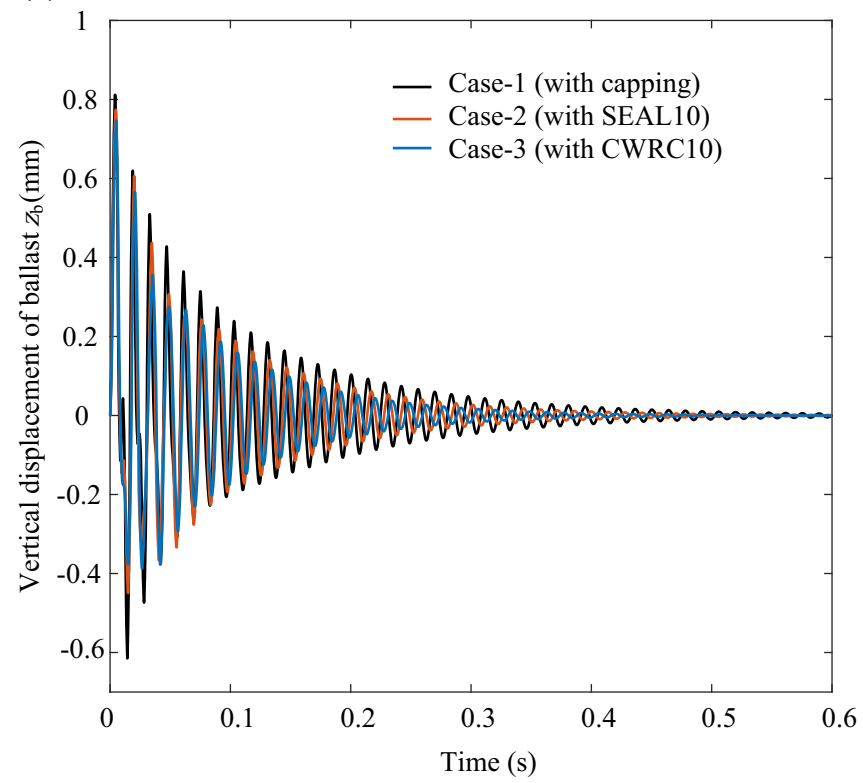

(b)

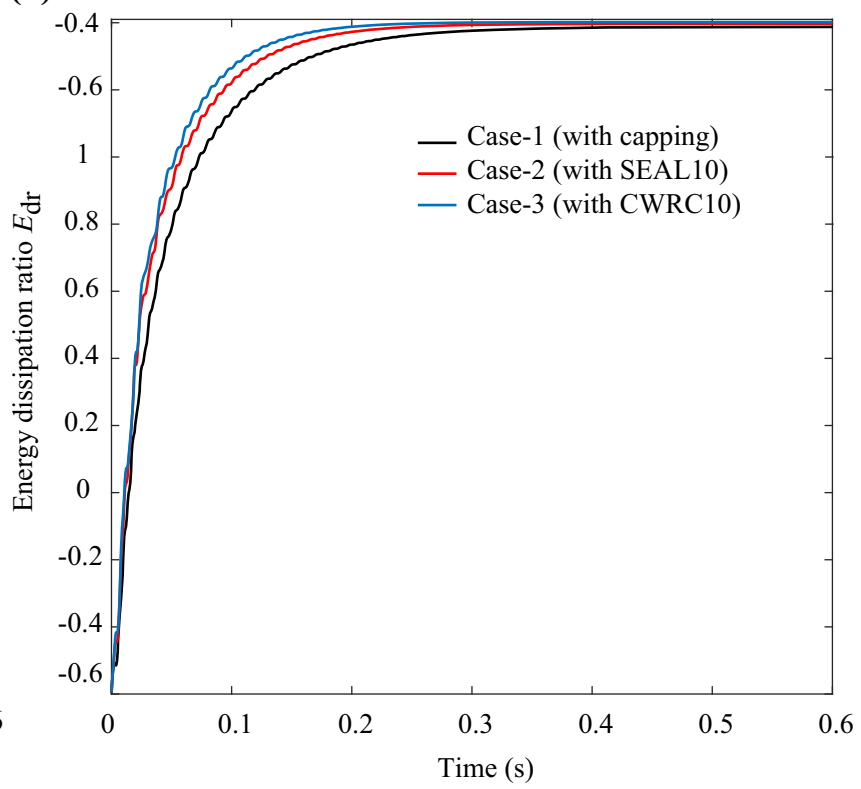

Fig. 21 Influence of alternate capping materials, SEAL10 and CWRC mixtures, on a displacement attenuation with time and b energy dissipation in the system under impact loads

track with traditional capping layer (case-1), SEAL10 (case-2) and CWRC10 (case-3). Since the optimum dynamic performance is achieved when the composition of rubber contents in SEAL mixture is $10 \%$ and CWRC mixtures is $10 \%$ [12, 28], the damping ratio and shear modulus of these materials are considered for dynamic analysis. It can be seen from Fig. 21a that at the moment of impact, the dynamic displacements peaked at $0.81 \mathrm{~mm}$ for the track with the traditional capping layer (case-1), which is slightly higher than that for the track on a concrete bridge deck (Fig. 21a). This is due to the lower stiffness for the track with capping and subgrade layers when compared to a rigid concrete deck. Figure 21a shows that when SEAL10 (case-2) and CWRC10 (case-3) mixtures are used, the initial dynamic vertical displacement of the ballast layer $\left(z_{\mathrm{b}}\right)$ was reduced by $5 \%$ and $8 \%$, respectively when compared to case- 1 . The track with CWRC10 mixture is found to be more effective in attenuation of displacements due to a lower stiffness of the material. Further, Fig. 21b shows that the time taken for the system to reach the steady state $\left(E_{\mathrm{dr}}=1\right)$ is reduced from $0.47 \mathrm{~s}$ to 0.34 and $0.28 \mathrm{~s}$ for case- 2 and case- 3 , respectively. This clearly shows that 
more energy is absorbed by the rubber crumbs, which provides additional damping and aids the track system to quickly attenuate the vibrations in ballast layer and reach the steady state.

Further, to investigate the influence of SEAL10 and CWRC10 on ballast and subgrade layers, the percentage of energy absorbed by each layer for the three cases is plotted in Fig. 22. It can be seen that the inclusion of SEAL10 and CWRC10 mixtures not only reduces the energy absorbed by ballast but also reduces the energy absorbed by subgrade. This reduction can be attributed to higher energy absorption by rubber crumbs in SEAL10 and CWRC10, which is significantly higher than that of the traditional capping layer as seen in Fig. 22. This enhanced energy absorption of the alternate capping materials would be beneficial not only to reduce the particle breakage of ballast, but also provides additional protection to the subgrade layers beneath the capping layer.

\section{Conclusions}

This paper reviews four novel applications in railways using recycled rubber products including CWRC mixtures and SEAL mixtures (mixtures of SFS, CW and RC) to replace subballast/capping materials, tyre cells reinforcements for subballast/capping layer and under ballast mats (UBMs). The energy dissipation capacity was investigated for each application via small-scale triaxial tests and largescale model tests using the track process simulation apparatus. The laboratory tests and the rheological model indicate that the four applications using recycled rubber could increase the energy absorbing capacity of the rail track and help to reduce the ballast degradation and deformation efficiently. The following findings can be drawn from this paper:

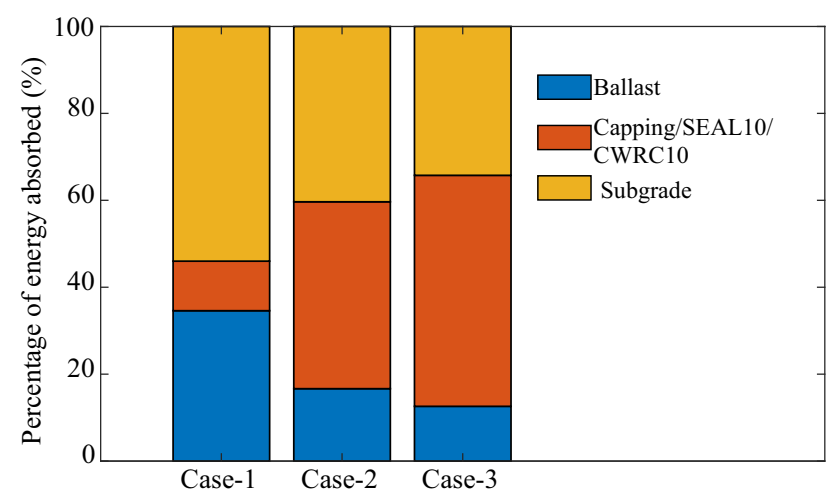

Fig. 22 Percentage of energy absorbed by each layer in a railway track
- The inclusion of rubber contents in CWRC mixtures increased the overall energy absorbing capacity and energy dissipation potential under static and cyclic loading. The compressibility of $\mathrm{RC}$ particles was captured by applying a rest period after a certain number of cyclic loading cycles. This enabled part of the energy dissipation potential to recover and further reduced the particle breakage of $\mathrm{CW}$.

- An energy dissipation flow chart was proposed for SEAL and a large-scale physical model was developed to validate the concept. It was found that by increasing the RC content in SEAL, the energy absorbing dissipation capacity of the track specimen increases, while more energy was dissipated through the deformation of the SEAL mixtures, hence reducing the ballast breakage. With SEAL10, the track specimen has less lateral dilation and settlement and significantly reduced ballast breakage $(58 \%)$ compared to traditional track.

- Large-scale laboratory tests showed that by confining the capping layer using a tyre cell infilled with spent ballast or crushed basalt in the model track specimen, the damping ratio and the dissipated energy increased and hence effectively reduced the ballast breakage (37.6\%-68.5\%), especially for large ballast particles (37.5 mm).

- By inserting a UBM at the ballast-concrete base interface, there is about $8 \%-22 \%$ reduction in the shear and volumetric strain for a 25-t axle load, and about $8 \%-16 \%$ reduction that of a 35-t axle load, and the overall ballast degradation was mitigated by $35 \%-$ $45 \%$. An empirical model was proposed to predict the total energy dissipation by capturing the ballast breakage and frictional sliding, and it was calibrated and validated using current and previous test data.

- The outcomes from laboratory investigations on shock mats (UBM), SEAL and CWRC mixtures were included in the track rheological model. Under impact loads, the model results showed the enhanced energy absorption capacity of a track when shock mats and alternate capping layers were used. The inclusion of shock mats reduced the dynamic displacements of ballast on concrete decks and aided in quick attenuation of the mechanical energy. For tracks on embankments, SEAL and CWRC mixtures absorbed most of the mechanical energy, thus reducing the potential for ballast breakage and preventing subgrade failure.

Acknowledgements The authors would like to acknowledge the financial assistance provided by the Australian Research Council (ARC) Linkage Project (LP200200915) and ARC Industry Transformation Training Centre for Advanced Rail Track Technologies (ARC-ITTC-Rail: IC170100006). The financial and technical 
assistance provided by industry partners including Australasian Centre For Rail Innovation (ACRI), Transport for NSW, RMS, Sydney Trains, SMEC, Bestech, Douglas Partners, ASMS, South32, Ecoflex International and Tyre Crumbs Australia is gratefully acknowledged. Salient contents have been modified from research outcomes published earlier and reproduced with kind permission from ASCE-J. Geotechnical \& Geoenvironmental Engineering, ASCE J. Materials in Civil Engineering, Transportation Geotechnics, and Transportation Engineering, among others.

Open Access This article is licensed under a Creative Commons Attribution 4.0 International License, which permits use, sharing, adaptation, distribution and reproduction in any medium or format, as long as you give appropriate credit to the original author(s) and the source, provide a link to the Creative Commons licence, and indicate if changes were made. The images or other third party material in this article are included in the article's Creative Commons licence, unless indicated otherwise in a credit line to the material. If material is not included in the article's Creative Commons licence and your intended use is not permitted by statutory regulation or exceeds the permitted use, you will need to obtain permission directly from the copyright holder. To view a copy of this licence, visit http://creativecommons. org/licenses/by/4.0/.

\section{References}

1. Wang S, Burton D, Herbst AH, Sheridan J, Thompson MC (2018) The effect of the ground condition on high-speed train slipstream. J Wind Eng Ind Aerodyn 172:230-243

2. Zhang Y, Zhang A, Wang J (2020) Exploring the roles of highspeed train, air and coach services in the spread of COVID-19 in China. Transp Policy 94:34-42

3. McIntosh J, Newman P, Glazebrook G (2013) Why fast trains work: an assessment of a fast regional rail system in Perth, Australia. J Transport Technol 3:37-47

4. Biabani MM, Ngo NT, Indraratna B (2016) Performance evaluation of railway subballast stabilised with geocell based on pullout testing. Geotext Geomembr 44(4):579-591

5. Leshchinsky B, Ling HI (2013) Numerical modeling of behavior of railway ballasted structure with geocell confinement. Geotext Geomembr 36:33-43

6. Zhao M, Zhang L, Zou X, Zhao H (2009) Research progress in two-direction reinforced composite foundation formed by geocell reinforced mattress and gravel piles. China J Highway Transport 22(1): $1-10$

7. Indraratna B, Qi Y, Ngo TN, Rujikiatkamjorn C, Neville T, Ferreira FB, Shahkolahi A (2019) Use of geogrids and recycled rubber in railroad infrastructure for enhanced performance. Geosciences 9(1):30

8. Leng J, Gabr MA (2002) Characteristics of geogrid-reinforced aggregate under cyclic load. Transp Res Rec 1786(1):29-35

9. Indraratna B, Ngo NT, Rujikiatkamjorn C (2011) Behavior of geogrid-reinforced ballast under various levels of fouling. Geotext Geomembr 29(3):313-322

10. Liu C, Indraratna B, Rujikiatkamjorn C (2020) An analytical model for particle-geogrid aperture interaction. Geotext Geomembr 49:41-44

11. Göbel CH, Weisemann UC, Kirschner RA (1994) Effectiveness of a reinforcing geogrid in a railway subbase under dynamic loads. Geotext Geomembr 13(2):91-99

12. Qi Y, Indraratna B, Heitor A, Vinod JS (2018) Effect of rubber crumbs on the cyclic behavior of steel furnace slag and coal wash mixtures. J Geotech Geoenviron Eng 144(2):04017107
13. Fonseca J, Riaz A, Bernal-Sanchez J, Barreto D, McDougall J, Miranda-Manzanares M, Marinelli A, Dimitriadi V (2019) Particle-scale interactions and energy dissipation mechanisms in sand-rubber mixtures. Géotech Lett 9(4):263-268

14. Kim H-K, Santamarina JC (2008) Sand-rubber mixtures (large rubber chips). Can Geotech J 45(10):1457-1466

15. Navaratnarajah SK, Indraratna B (2017) Use of rubber mats to improve the deformation and degradation behavior of rail ballast under cyclic loading. J Geotech Geoenviron Eng 143(6):04017015

16. Costa PA, Calçada R, Cardoso AS (2012) Ballast mats for the reduction of railway traffic vibrations. Numerical study. Soil Dyn Earthq Eng 42:137-150

17. Jayasuriya C, Indraratna B, Ngo TN (2019) Experimental study to examine the role of under sleeper pads for improved performance of ballast under cyclic loading. Transport Geotech 19:61-73

18. Indraratna B, Qi Y, Jayasuriya C, Rujikiatkamjorn C, Arachchige CM (2021) Use of recycled rubber inclusions with granular waste for enhanced track performance. Transport Eng 6:100093

19. Indraratna B, Qi Y, Tawk M, Heitor A, Rujikiatkamjorn C, Navaratnarajah SK (2020) Advances in ground improvement using waste materials for transportation infrastructure. In: Proceedings of the institution of civil engineers-ground improvement, pp 1-44

20. Indraratna B, Sun Q, Grant J (2017) Behaviour of subballast reinforced with used tyre and potential application in rail tracks. Transport Geotech 12:26-36

21. Mohajerani A, Burnett L, Smith JV, Markovski S, Rodwell G, Rahman MT, Kurmus H, Mirzababaei M, Arulrajah A, Horpibulsuk S (2020) Recycling waste rubber tyres in construction materials and associated environmental considerations: a review. Resour Conserv Recycl 155:104679

22. Sol-Sánchez M, Thom N, Moreno-Navarro F, Rubio-Gamez M, Airey G (2015) A study into the use of crumb rubber in railway ballast. Constr Build Mater 75:19-24

23. Koohmishi M, Azarhoosh A (2020) Hydraulic conductivity of fresh railway ballast mixed with crumb rubber considering size and percentage of crumb rubber as well as aggregate gradation. Constr Build Mater 241:118133

24. Arachchige CM, Indraratna B, Qi Y, Vinod JS, Rujikiatkamjorn C (2021) Geotechnical characteristics of a rubber intermixed ballast system. Acta Geotech 1-12

25. Indraratna B, Qi Y, Heitor A (2018) Evaluating the properties of mixtures of steel furnace slag, coal wash, and rubber crumbs used as subballast. J Mater Civ Eng 30(1):04017251

26. Qi Y, Indraratna B (2020) Energy-based approach to assess the performance of a granular matrix consisting of recycled rubber, steel-furnace slag, and coal wash. J Mater Civ Eng 32(7):04020169

27. Qi Y, Indraratna B (2021) The influence of rubber inclusion on the dynamic response of rail track. J Mater Civ Eng 34(2):04021432

28. Tawk M, Qi Y, Indraratna B, Rujikiatkamjorn C, Heitor A (2021) Behavior of a mixture of coal wash and rubber crumbs under cyclic loading. J Mater Civ Eng 33(5):04021054

29. Saberian M, Li J, Nguyen B, Wang G (2018) Permanent deformation behaviour of pavement base and subbase containing recycle concrete aggregate, coarse and fine crumb rubber. Constr Build Mater 178:51-58

30. Arulrajah A, Naeini M, Mohammadinia A, Horpibulsuk S, Leong M (2020) Recovered plastic and demolition waste blends as railway capping materials. Transport Geotech 22:100320

31. Naeini M, Mohammadinia A, Arulrajah A, Horpibulsuk S, Leong M (2019) Stiffness and strength characteristics of demolition waste, glass and plastics in railway capping layers. Soils Found 59(6):2238-2253 
32. Disfani MM, Tsang H-H, Arulrajah A, Yaghoubi E (2017) Shear and compression characteristics of recycled glass-tire mixtures. J Mater Civ Eng 29(6):06017003

33. Wang D, Tawk M, Indraratna B, Heitor A, Rujikiatkamjorn C (2019) A mixture of coal wash and fly ash as a pavement substructure material. Transport Geotech 21:100265

34. Kim B, Prezzi M, Salgado R (2005) Geotechnical properties of fly and bottom ash mixtures for use in highway embankments. J Geotech Geoenviron Eng 131(7):914-924

35. Kaniraj SR, Gayathri V (2003) Geotechnical behavior of fly ash mixed with randomly oriented fiber inclusions. Geotext Geomembr 21(3):123-149

36. Signes CH, Fernández PM, Perallón EM, Franco RI (2015) Characterisation of an unbound granular mixture with waste tyre rubber for subballast layers. Mater Struct 48(12):3847-3861

37. Rujikiatkamjorn C, Indraratna B, Chiaro G (2013) Compaction of coal wash to optimise its utilisation as water-front reclamation fill. Geomech Geoeng 8(1):36-45

38. Kaliboullah CI (2016) Behaviour of compacted coalwash under saturated condition incorporating particle breakage. School of Civil, Mining and Environmental Engineering, University of Wollongong

39. Chiaro G, Indraratna B, Tasalloti SA, Rujikiatkamjorn C (2015) Optimisation of coal wash-slag blend as a structural fill. Institution of Civil Engineers: Ground Improvement

40. Tawk M, Indraratna B (2021) Role of rubber crumbs on the stress-strain response of a coal wash matrix. J Mater Civ Eng 33(3):04020480

41. Indraratna B, Rujikiatkamjorn C, Tawk M, Heitor A (2019) Compaction, degradation and deformation characteristics of an energy absorbing matrix. Transport Geotech 19:74-83

42. Indraratna B, Lackenby J, Christie D (2005) Effect of confining pressure on the degradation of ballast under cyclic loading. Geotechnique 55(4):325-328

43. Qi Y, Indraratna B, Heitor A, Vinod JS (2019) Closure to "effect of rubber crumbs on the cyclic behavior of steel furnace slag and coal wash mixtures." J Geotech Geoenviron Eng 145(1):07018035

44. Feng Z-Y, Sutter KG (2000) Dynamic properties of granulated rubber/sand mixtures. Geotech Test J 23(3):338-344

45. Li B, Huang M, Zeng X (2016) Dynamic behavior and liquefaction analysis of recycled-rubber sand mixtures. J Mater Civ Eng 28(11):04016122

46. Jeffs T, Tew GP (1991) A review of track design procedures: sleepers and ballast, in Railways of Australia, Melbourne, Australia

47. Indraratna B, Nimbalkar S, Rujikiatkamjorn C (2014) Enhancement of rail track performance through utilisation of geosynthetic inclusions. Geotech Eng J SEAGS AGSSEA 45(1):17-27

48. ASTM-D4885-01 (2018) Standard test method for determining performance strength of geomembranes by the wide strip tensile method. ASTM International

49. American Society for Testing and Materials (2003) D3999-91. Standard test methods for the determination of the modulus and damping properties of soils using the cyclic triaxial apparatus. In: Annual Book of ASTM Standard

50. Indraratna B, Sun Q, Heitor A, Grant J (2018) Performance of rubber tire-confined capping layer under cyclic loading for railroad conditions. J Mater Civ Eng 30(3):06017021

51. Indraratna B, Salim W, Rujikiatkamjorn C (2011) Advanced rail geotechnology-ballasted track. CRC Press

52. Kaewunruen S, Remennikov AM (2006) Sensitivity analysis of free vibration characteristics of an in situ railway concrete sleeper to variations of rail pad parameters. J Sound Vib 298(1-2):453-461

53. Johansson A, Nielsen JC, Bolmsvik R, Karlström A, Lundén R (2008) Under sleeper pads-influence on dynamic train-track interaction. Wear 265(9-10):1479-1487

54. Tiwari B, Ajmera B, Moubayed S, Lemmon A, Styler K (2012) Soil modification with shredded rubber tires. In: GeoCongress 2012: state of the art and practice in geotechnical engineering, Oakland, California, March 25-29, pp 3701-3708

55. Sol-Sánchez M, Moreno-Navarro F, Rubio-Gámez MC (2014) Viability of using end-of-life tire pads as under sleeper pads in railway. Constr Build Mater 64:150-156

56. Ajmera B, Tiwari B, Koirala J (2016) Geotechnical properties of clays modified with recycled crumb rubber. In: Geotechnical and structural engineering congress 2016, Phoenix, Arizona, February $14-17$

57. DIN (2010) Mechanical vibration-resilient elements used in railway tracks. Part V: Laboratory test procedures for underballast mats. German Institute for Standardization, Berlin

58. Bolton M, Nakata Y, Cheng Y (2008) Micro-and macro-mechanical behaviour of DEM crushable materials. Géotechnique 58(6):471-480

59. Liu M, Gao Y, Liu H (2014) An elastoplastic constitutive model for rockfills incorporating energy dissipation of nonlinear friction and particle breakage. Int $\mathbf{J}$ Numer Anal Methods Geomech 38(9):935-960

60. Nimbalkar S, Indraratna B (2016) Improved performance of ballasted rail track using geosynthetics and rubber shockmat. J Geotech Geoenviron Eng 142(8):04016031

61. Indraratna B, Nimbalkar S, Christie D, Rujikiatkamjorn C, Vinod J (2010) Field assessment of the performance of a ballasted rail track with and without geosynthetics. J Geotech Geoenviron Eng 136(7):907-917

62. Punetha P, Nimbalkar S, Khabbaz H (2020) Analytical evaluation of ballasted track substructure response under repeated train loads. Int J Geomech 20(7):04020093

63. Nimbalkar S, Indraratna B, Dash SK, Christie D (2012) Improved performance of railway ballast under impact loads using shock mats. J Geotech Geoenviron Eng 138(3):281-294

64. Chen JY, Ummin O, Yu T, Qi YJ (2013) Applications of Rayleigh wave detection technique and polymer grouting technology in waterproof construction. In: Applied mechanics and materials. Trans Tech Publ. 